\title{
Extracting Inflation from Stock Returns to Test Purchasing Power Parity*
}

\section{Bhagwan Chowdhry, Richard Roll, and Yihong Xia ${ }^{\dagger}$}

Revised: June 1, 2004

\footnotetext{
*The authors thank Werner Antweiler for providing the foreign exchange rate data; Kent Daniel, Ken French and Xiaoyan Zhang for providing the Fama-French factor returns data; Ben Bernanke (the Editor), three anonymous referees, Marshall Blume, Michael Brennan, Nai-fu Chen, John Cochrane, Bernard Dumas, Philippe Jorion, Andrew Karolyi, Yrjö Koskinen, seminar participants at the $10^{\text {th }}$ Georgian Tech International Finance Conference, California State University Fullerton, HEC France, the Stockholm School of Economics, and the brown-bag lunch seminar series at Wharton for useful comments on earlier drafts of the paper. Xia acknowledges the financial support from the Weiss Center at the Wharton School, University of Pennsylvania. All remaining errors are ours.

${ }^{\dagger}$ Chowdhry and Roll are at The Anderson School at UCLA, 110 Westwood Plaza, Los Angeles, CA 900951481. Phone: (310) 825-5883 (Chowdhry), (310) 825-6118 (Roll). Fax: (775) 248-6567 (Chowdhry), (310) 206-8604 (Roll). Email: bhagwan@anderson.ucla.edu, rroll@anderson.ucla.edu. Xia is at Department of Finance, The Wharton School, University of Pennsylvania, Philadelphia, PA 19104. Phone: (215) 898-3004. Fax: (215) 898-6200. E-mail: yxia@wharton.upenn.edu.
} 


\title{
Extracting Inflation from Stock Returns to Test Purchasing Power Parity
}

\begin{abstract}
Relative purchasing power parity (PPP) holds for pure price inflations, which affect prices of all goods and services by the same proportion, while leaving relative prices unchanged. Pure price inflations also affect nominal returns of all traded financial assets by exactly the same amount. Recognizing that relative PPP may not hold for the official inflation data constructed from commodity price indices because of relative price changes and other frictions that cause prices to be "sticky," we provide a novel method for extracting a proxy for realized pure price inflation from stock returns. We find strong support for relative PPP in the short run using the extracted inflation measures.
\end{abstract}




\section{Extracting Inflation from Stock Returns to Test Purchasing Power Parity}

Purchasing power parity $(\mathrm{PPP})$ is the simple proposition that prices in different countries should be equal if they are converted to the same currency. The absolute version of PPP is based on the law of one price, which maintains that arbitrage should tend to equilibrate prices of the same good at different locations. If the composition of the basket of goods used for constructing price indices is identical across countries, PPP trivially follows from the law of one price.

However, frictions to goods arbitrage such as transportation costs and other impediments to trade, the extreme being non-tradable goods such as land, inhibit cross-country price equalization. Even with such frictions, the relative version of PPP, which maintains that the change in price levels across countries should be the same after adjusting for the change in the exchange rate, may still hold if relative price changes across countries are identical. For instance, a pure money shock will change nominal prices of all goods, services and assets by exactly the same amount so that relative prices among different assets will remain constant. In this strict pure price inflation case, the relative version of PPP will hold.

Although simple, the PPP hypothesis has defied empirical confirmation for decades. There seems to be little agreement about why it fails so spectacularly when taken to data. ${ }^{1}$ The absolute version of PPP may fail because of the above mentioned frictions to goods arbitrage, and is not the focus of this paper. Our focus instead is on the failure of relative PPP.

\footnotetext{
${ }^{1}$ Rather than provide a long list of relevant references here, we point the reader to an excellent survey by Rogoff (1996).
} 
The failure of relative PPP in its most basic form can be described as follows. If relative PPP holds, then changes in the exchange rate must equal the concurrent inflation differential between two countries. Empirically, the two are at most weakly correlated (Rogoff, 1996). Furthermore, changes in exchange rates are extremely volatile, with a yearly standard deviation typically on the order of $12-13 \%$ for developed countries, while inflation differentials have yearly standard deviations less than 1\% (see Rogoff, 1998). This empirical regularity has led scholars to wonder if exchange rate movements are "too" volatile to be explained by fundamentals. An alternative explanation consistent with the empirical regularity of high relative volatility of exchange rates is that prices of goods and services that are "too sticky." Whether small menu costs or other transactions costs can create such a sluggish response in prices of goods and services has been debated in the literature theoretically and empirically (see Rotemberg, 1982, Mankiw, 1985, Krugman, 1986, Dixit, 1989a, 1989b and Delgado, 1991). We make little contribution to this debate. Our contribution is in demonstrating that nominal price rigidities in the goods market may indeed be responsible for the failure of relative PPP and once a proxy for the unobservable pure price inflation is found, relative PPP does hold, with the volatility of the inflation differentials being the same order of magnitude as the volatility of exchange rates.

We suspect that if consumption goods and services were freely and continuously traded in the same way as stocks, bonds or foreign currencies, they would display price movements similar to that of financial assets and would be much more volatile than what a consumer observes in, say, a grocery store. But goods and services are not freely and continuously traded in financial markets, and their prices are sluggish in responding to monetary shocks 
(Dornbusch, 1976), news and consumer/investor expectations and sentiments. Moreover, if nominal prices were not "sticky," they would adjust not only to current monetary shocks and news or rumors in the market, but also to shocks that affect consumers/investors expectations of future price levels, as argued by Mussa (1982). Mussa suggests that "information that changes these expectations can have a profound effect..., even if the current observed change that embodies this information is seemingly not very large." Consistent with the arguments of Barr and Campbell (1997), it seems possible that high frequency variation in forward looking price levels may be driven by "inflation scares" - scares that inflation may jump to very high levels or even spiral into hyper-inflation. Inflation scares, however, may turn out to be justified only rarely and, as a result, the realized inflation series constructed with "sticky" commodity prices may not appear to be volatile. This is analogous to the "peso problem" in which spot prices of a pegged currency, interspersed with infrequent but large devaluations, may appear to be smooth for long periods; the high frequency fluctuations in forward prices of such a currency may be reflecting changing expectations of the size and possibility of devaluation. This suggests that the "true" unobservable pure price inflation is likely to be much more volatile at high frequencies than indicated by the official inflation measures derived from price indices.

Thus, one resolution of the PPP puzzle may come from using long horizon tests. This is extensively discussed in the literature and indeed, PPP does tend to hold much better in the long run (Rogoff, 1996). An alternative strategy may be to obtain a high frequency proxy for the unobservable pure price inflation. We wondered whether the PPP puzzle might be resolved in the short run as well by such a proxy, which would be free from problems of 
nominal rigidities, transaction costs, aggregation, and relative price changes often associated with official price measures such as the CPI. We attempt to answer this question here by providing a novel method for extracting high frequency "non-sticky" inflation proxies from stock returns. $^{2}$

The essence of our method boils down to estimating the nominal return on a real risk-free asset. We label such a return the "ex-post" nominal risk-free rate, because this rate includes both the real risk-free rate and the realized inflation rate during the period. Nominal returns on a traded risk-free asset would provide the most direct surrogate for our test of relative PPP in the short run. Unfortunately, there are no traded real risk-free assets available in the economy. Treasury bills are nominal risk-free assets, so their returns only measure nominal returns on nominal risk-free assets, which are risky in real terms due to the presence of unexpected inflation. Indexed securities such as Treasury Inflation Protected Securities (TIPS) are often considered real risk-free assets, but they are only available for a limited time period and their returns are affected by contractual peculiarities. ${ }^{3}$ One problem with U.S. TIPS, for example, is that their coupon payments are indexed to official inflation derived from the CPI, which is exactly the series we are trying to replace in our analysis.

In this study, we propose to extract the unobservable "ex-post" nominal risk-free rate from nominal equity returns, which are readily available at high frequency and are very responsive to news and investor expectations. Nominal equity returns, however, must be purged of influences of real factors in order to get an estimate of the "ex-post" nominal

\footnotetext{
${ }^{2}$ Stock and Watson (2003) provide an excellent survey of research on forecasting economic activity and inflation using asset prices.

${ }^{3}$ The US TIPS only started trading in January 1997. The UK has longer history of trading TIPS, but they are not very well indexed. The lag is eight months between CPI changes and the revision in the coupon payment of UK's TIPS; this induces a lot of nominal risk and pollutes the real yields.
} 
risk-free rate. A good asset pricing model will help minimize the residual real effects left in the extracted series, and we adopt the empirically successful Fama-French three-factor model (and an extension that includes momentum as a fourth factor) to describe the return generating process. An empirically - instead of a theoretically - motivated model is chosen to ensure that none of the widely recognized and empirically successful common factors are omitted in purging the real effects from equity returns. A series extracted from the realized equity returns that is orthogonal to the common real factors will give a good measure of the "ex-post" nominal risk-free rate. Our empirical procedure relies on the familiar FamaMacBeth (1973) approach to extract such a series.

When the extracted proxies are used to replace the official CPI inflation measure in the PPP test, we find that relative PPP holds well in the short run in both single-country-pair OLS regressions and a pooled system regression. Results from our robustness checks suggest that our supportive evidence for short-run relative PPP is unlikely to be driven by missing world factors or by real effects of inflation. An examination of our extracted series and the CPI indicates long run cointegration between the price level constructed from our series and the price level measured by the CPI, even though these two variables are only weakly correlated in the short run. This implies that the official CPI series may be a smoothed measure of inflation in the long run, while the inflation measure extracted from asset prices better captures temporary swings in inflation and inflation scares. Therefore, our results complement the findings from the long-run PPP tests, and help resolve the PPP puzzle in the short run.

The rest of the paper is organized as follows: Section I introduces the theoretical frame- 
work and presents a detailed derivation of the empirical methodology; Section II describes the data; Section III presents empirical results and carries out robustness checks; Section IV summarizes and concludes the paper.

\section{Theoretical Framework and Empirical Methodology}

In this section, we first present the factor model for stock returns and derive the empirical method for extracting the "ex-post" nominal risk-free rate from stock returns. In the second subsection, we report the PPP test using our extracted inflation series.

\subsection{Extracting the Nominal Risk-free Rate from Stock Returns}

To study PPP, we require estimates of the pure price inflation, which is linerly related to the nominal return on a real risk-free asset:

$$
R_{f t} \equiv r_{f t}+\pi_{t}
$$

where $r_{f t}$ denotes the realized real risk-free rate and $\pi_{t}$ denotes the realized pure price inflation for the period from date $t-1$ to $t$. The most obvious way to obtain $R_{f t}$ is to use the nominal return on a traded risk-free asset, and the widely used Treasury Bill rates come to mind. Unfortunately, Treasury Bill rates are the nominal rates on nominal risk-free assets. Treasury Bill rates for period from date $t-1$ to $t, T B_{t-1}$, are determined at date $t-1$ (at the beginning of the period) based on investors' expectations of the real rates and the inflation for period from date $t-1$ to $t$. What happens if there is a $1 \%$ unexpected pure price inflation during this period? The rate $T B_{t-1}$ is not affected because it is fixed at date $t-1$, but the nominal return on a real risk-free asset $R_{f t}$, which is realized at the end 
of the period, goes up by $1 \%$ since it is indexed by the realized pure price inflation during the period from $t-1$ to $t$. Therefore, $R_{f t}$ instead of $T B_{t-1}$ is the correct variable to use in testing relative PPP relation.

As we mentioned earlier, one should not use the realized nominal returns on securities such as Treasury Inflation Protected Securities (TIPS) as a measure of $R_{f t}$ either, because the coupons on these securities are indexed to official inflation data such as the changes in the CPI, which we argue is not a good measure of pure price inflation.

The alternative is to extract $R_{f t}$ from observable nominal returns on risky financial assets. Financial asset prices have some advantages over commodity prices. First, financial asset prices capture all relevant information and summarize investors' expectations or perceptions of the economy including inflation. Moreover, financial asset prices are readily available without any time lag or any problems of aggregation. Therefore, pure price inflation extracted from asset returns, as compared to official inflation data, is likely to be more responsive to "news" or "perceptions" in financial markets and is relatively unaffected by frictions such as transportation costs and nominal rigidities.

Since risky asset returns are influenced by many real factors, the "ex-post" nominal risk-free returns can only be extracted after we purge nominal asset returns of influences of real factors. This requires an asset pricing model. Instead of developing an asset pricing model from fundamentals, we adopt the practical view that an empirically successful model can capture, at least in sample, most real effects in asset returns, allowing us to extract a relatively good estimate of the "ex-post" nominal risk-free return.

We adopt the popular Fama-French three-factor model (and an extension that includes 
momentum as a fourth factor) to describe the excess real return generating process:

$$
r_{i t}-r_{f t}=\sum_{k=1}^{3} \beta_{i k} f_{k t}+\epsilon_{i t}
$$

where $r_{i t}$ is the real return on asset $i$ for the period from $t-1$ to $t, r_{f t}$ is the real risk-free rate, and the three factors $f_{k t}$ are approximated by Fama-French three factors: (1) returns on the market index in excess of the risk-free rate, $r_{M t}-r_{f t}$, (2) returns on the zero-investment SMB portfolio, $r_{S t}-r_{B t}$, where $r_{S t}\left(r_{B t}\right)$ is the return on a small (big) cap portfolio, and (3) returns on the zero-investment HML portfolio, $r_{H t}-r_{L t}$, where $r_{H t}\left(r_{L t}\right)$ is the return on a high (low) book-to-market portfolio. In addition, $\epsilon_{i t}$ is a spherical disturbance and the $\beta$ 's are constant factor loadings.

Equation (1) applies to real returns, but we only observe nominal returns for financial assets. To transform the real return generating process to nominal returns, we further assume that the Fisher equation holds so that

$$
R_{i t}=r_{i t}+\pi_{t}, \quad \forall i
$$

where $r_{i t}$ denotes the real return on asset $i, R_{i t}$ denotes its nominal correspondent, while $\pi_{t}$ stands for the pure price inflation. Note that the expected and unexpected inflation may have real effects on asset returns and the real effect may be different for different assets. ${ }^{4}$ To derive a tractable empirical model, we assume that all potential real effects, including the real effects of inflation, are captured by the three factors. Under this assumption, $r_{i t}$ captures all the real effects while $\pi_{t}$ only measures pure price inflation that is free from any

\footnotetext{
${ }^{4}$ Boudoukh, Richardson and Whitelaw (1994) argue that expected inflation may be correlated with future production and thus affect real stock returns. We will later check the impact of adding expected inflation as an additional factor in the model.
} 
real effects and is thus orthogonal to $r_{i t}(\forall i)$. By definition, $\pi_{t}$ has a one-to-one relation with all nominal returns $R_{i t}(\forall i)$ and does not induce differential changes in nominal returns. To illustrate this idea, consider a real event such as the assassination of Colosio in March 1994 in Mexico. The peso depreciated against the U.S. dollar when the assassination took place. The Mexican peso prices of arbitragable assets, such as Gold, rose as a result of the exchange rate depreciation but, at the same time Mexican peso relative prices of other assets must have declined because there was no immediate pure inflation, $\pi_{t}$. The depreciation of the Mexican peso in this case was real. In contrast, if the Mexican government decided to increase the money supply, all nominal returns would increase and the common component in returns attributable to $\pi_{t}$ would be significant. The Mexican peso would depreciate in this case as well but there would be little, if any, depreciation of the currency in real terms.

In comparison, the official CPI inflation is calculated from a basket of consumption goods. For the purpose of testing PPP, CPI inflation is contaminated by the movement in relative prices across different goods in the basket, the change in the composition of the basket and the presence of non-traded commodities.

Under the assumption of $R_{i t}=r_{i t}+\pi_{t}$, the return generating process given in equation (1) can be formulated in terms of observable nominal returns

$$
R_{i t}-R_{f t}=\beta_{i 1}\left[R_{M t}-R_{f t}\right]+\beta_{i 2}\left[R_{S t}-R_{B t}\right]+\beta_{i 3}\left[R_{H t}-R_{L t}\right]+\epsilon_{i t},
$$

where $R_{f t} \equiv r_{f t}+\pi_{t}$ is the unobservable "ex-post" nominal risk-free return. To estimate $R_{f t}$, we employ the standard two-stage Fama-MacBeth (1973) regression methodology.

In the first stage, a time series regression is carried out to estimate the betas. To capture 
any possible mispricing of the model, an intercept $\alpha_{i}$ is introduced to (2), which is then rewritten as follows:

$$
R_{i t}-T B_{t-1}=\alpha_{i}+\beta_{i 1}\left[R_{M t}-T B_{t-1}\right]+\beta_{i 2}\left[R_{S t}-R_{B t}\right]+\beta_{i 3}\left[R_{H t}-R_{L t}\right]+\eta_{i t}
$$

where

$$
\eta_{i t} \equiv\left(1-\beta_{i 1}\right)\left[R_{f t}-T B_{t-1}\right]+\epsilon_{i t}
$$

Since $T B_{t-1}=\mathrm{E}_{t-1}\left[R_{f t}\right], R_{f t}-T B_{t-1}$ measures the unexpected inflation (plus the real rate) realized during the period. The error term $\eta_{i t}$ is comprised of two mean zero terms: the idiosyncratic risk, $\epsilon_{i t}$, and a linear function of the market wide unexpected inflation (plus the real rate), $\left(1-\beta_{i 1}\right)\left[R_{f t}-T B_{t-1}\right]$.

The second stage of estimation consists of a cross-sectional regression on each date $t$. Rewriting equation (1), and including the mispricing term $\hat{\alpha}_{i}$ :

$$
R_{i t}-\hat{\alpha}_{i}=\hat{R}_{f t}+\sum_{k=1}^{3} f_{k t} \hat{\beta}_{i k}+\epsilon_{i t} \quad \forall i
$$

The intercept of the above cross-sectional regression of stock returns (minus the possible mispricing) on the three factor betas provides the estimate of $R_{f t}$. While the traditional Fama-MacBeth approach yields a time series estimate of $\hat{R}_{f t}$, most researchers are only interested in its sample mean $\bar{R}_{f t} \equiv \frac{1}{T} \sum_{t=1}^{T} \hat{R}_{f t}$. We, however, are mainly interested in the time series behavior of $\hat{R}_{f t}$.

In our first stage time-series regression, the nominal returns in excess of the Treasury bill rate are regressed on the excess market portfolio returns and the two Fama-French factor returns. To mitigate estimation errors in the betas, we employ industry portfolios 
for both domestic and foreign stocks as the base assets. This step produces estimates of the betas. Notice that because the error term $\eta_{i t}$ in (3) includes unexpected inflation, it may be correlated with the realized nominal return on the market and consequently bias the estimate of $\beta$ 's. ${ }^{5}$

The Fama-French factors are created using domestic stocks only. One might argue that with integrated world capital markets, return generating factors might include some world factors as well. ${ }^{6}$ If world factors were included, however, we would have to convert returns denominated in foreign currencies into domestic units, which then introduce a foreign exchange rate component in our estimates. We want to avoid having exchange rates appear in both the dependent and independent variables in our PPP tests. Furthermore, Griffin (2002) finds that domestic Fama-French factors explain much more time-series variation in returns and generally have lower pricing errors than the (Fama-French) world factor model.

Note that the "ex-post" nominal risk-free rate differential, $R_{f t}^{*}-R_{f t}$, includes both pure price inflation differential, $\pi_{t}^{*}-\pi_{t}$, and the real interest-rate differential, $r_{f t}^{*}-r_{f t}$, (where foreign variables are denoted with superscript ${ }^{*}$ ). Since the real interest rate differential is

\footnotetext{
${ }^{5}$ In general, the fact that $\beta$ 's are estimated in the first stage and then used in the second stage as regressors introduce the errors-in-variable problem in the second-stage regression. Although a single-step regression can avoid this problem, it is infeasible in our current setting, where we are interested in the whole time series estimates of $\hat{R}_{f t}$. Pagan (1984) shows, in the setting of using estimated variables as regressors, that the two-step estimator is consistent and asymptotically efficient and there is no efficiency gain by switching to a full MLE, despite the result that the parameter variances are estimated inconsistently. Shanken (1992) provides standard error corrections for the second-stage parameter estimates. Since we are only interested in the point estimates, a correction for the standard errors is not relevant here.

${ }^{6}$ For example, Ang and Bekaert (2001) find that the U.S. rate is a stronger instrument than local ones in predictive regressions when the local excess returns are converted into U.S. returns, lending support for a globally integrated market. We later check the impact of adding the U.S. short rate as an additional factor in our model and find that our PPP results are virtually unchanged. Zhang (2003) also finds that the international CAPM with foreign exchange risk performs better than the single beta international CAPM and the Fama-French international three factor model. We later check whether our time series regression residuals are related to a world factor proxied by the Morgan Stanley Composite Index (MSCI), which is almost perfectly correlated with the Datastream Global Index used by Zhang (2003).
} 
unobservable, it is only feasible for us to use the "ex-post" nominal risk-free rate differential to approximate for the inflation differential. This approximation is harmless for the purpose of testing PPP relation if we put the noisy approximation on the left hand side of the regression and if the real interest rate differential $r_{f t}^{*}-r_{f t}$ is correlated neither with the pure price inflation differential nor with the foreign exchange rate changes. ${ }^{7}$ From a theoretical point of view, many general equilibrium models often assume that the real interest rate in the economy is determined by fundamentals such as the productivity of the economy and is uncorrelated with either realized pure price inflation or foreign exchange rates. Empirically speaking, although several recent papers find a positive relationship between real interest rate differentials and the spot rate changes over the long run $(3-5$ years $),{ }^{8}$ there is virtually no covariation between the two variables with a horizon less than one year. Since we are interested in examining the PPP in the short run at the monthly, bi-monthly and quarterly horizons, the contamination of the realized inflation measure by the realized real interest rate differentials will be unlikely to bias our estimate, although it will reduce the regression $R^{2}$ and affect the calculation of the standard error.

\subsection{Testing PPP}

The final step is the test of the PPP hypothesis. The relative PPP hypothesis implies that

$$
\Delta s_{t}=\Delta \pi_{t} \equiv \pi_{t}^{*}-\pi_{t}
$$

\footnotetext{
${ }^{7}$ For example, Adler and Lehman (1983) assumes that real interest rate differential is constant and thus satisfies both conditions.

${ }^{8}$ See, for example, Edison and Pauls (1993), Baxter (1994), and Bleaney and Laxton (2003).
} 
where $s_{t}$ denote the logarithm of the nominal exchange rate defined as the price of domestic currency in units of foreign currency (e.g., yen per dollar) and $\pi_{t}^{*}$ and $\pi_{t}$ denote the change in $\log$ price indices and thus are the inflation rates in foreign and domestic countries respectively.

Although the theory itself does not specify whether $\Delta \pi$ or $\Delta s$ should be the dependent variable, changes in spot rates are usually regressed on the inflation differentials in the empirical test of relative PPP:

$$
\Delta s_{t}=\delta+\gamma \Delta \pi_{t}+\varepsilon_{t}
$$

where $\delta+\varepsilon$ captures the movement of spot rate changes unaccounted for by inflation differentials. Under the null hypothesis that relative PPP holds, we have $H_{0}: \delta=0$ and $\gamma=1$. The alternative $\delta \neq 0$ suggests that exchange rates, on average, move for other reasons as well, which contribute to the higher volatility of exchange rate changes, while the alternative $\gamma>1$ incorporates the possibility of exchange rate overshooting models (Dornbusch, 1976).

It seems natural to put $\Delta s$ as independent variables simply because it is much more volatile than the problematic official CPI inflation differentials. The implicit assumption behind this conventional regression specification seems to imply that measurement errors or noises in foreign exchange rate changes are more severe than those in the inflation differentials, even though the exchange rates are directly determined in the market and should be more reliable measures than official indices.

Unlike the conventional specification, we test the relative PPP hypothesis by regressing $\Delta \pi$ on $\Delta s$. This is because $\Delta s$ is directly measured in the market price while we can only at best use $\Delta \hat{R}_{f t} \equiv \hat{R}_{f t}^{*}-\hat{R}_{f t}$ as a surrogate for $\Delta \pi$ and, as explained in the previous 
sub-section, $\hat{R}_{f t}$ contains substantial noise. Our regression specification is thus given by

$$
\Delta \hat{R}_{f t}=a+b \Delta s_{t}+\epsilon_{t}
$$

which is the observable counterpart to $\Delta \pi_{t}+\left(r_{f t}^{*}-r_{f t}\right)=a+b \Delta s_{t}+\varepsilon_{t}$. Under the null hypothesis that PPP holds so that $\sigma\left(\Delta \pi_{t}\right) \approx \sigma\left(\Delta s_{t}\right), b=1$. Moreover, the intercept of the regression is given by the mean real interest rate differential. If the average real interest rates in foreign and domestic countries are close to each other during the sample period, then we would expect $a=0$ under the null.

Our null hypothesis is that PPP holds if we have a good measure of the unobservable pure price inflation. An obvious alternative argument, widely used in the literature, is that inflation is measured correctly by the official series, but relative PPP fails for other reasons. Two well-known alternatives are exchange rate overshooting so that $\gamma>1$ and excess exchange rate volatility unrelated to inflation differential so that $\sigma^{2}\left(\Delta s_{t}\right)>\sigma^{2}\left(\Delta \pi_{t}\right)$. Under both these alternatives, the slope coefficient would be close to zero.

The specification of (7) could be easily confused with the specification of the Uncovered Interest Rate Parity (UCIRP) relation, which states that the expected change in the exchange rates equals the nominal interest rate differentials. ${ }^{9}$ In our notation, this is equivalent to testing the following relation:

$$
\mathrm{E}_{t-1}\left(\Delta s_{t}\right)=T B_{t-1}^{*}-T B_{t-1}
$$

where the foreign and domestic Treasury bill rates, $T B_{t-1}^{*}$ and $T B_{t-1}$, are pre-determined at

\footnotetext{
${ }^{9}$ Numerous empirical studies find that uncovered interest rate parity does not hold, leading to the conjecture that foreign exchange rate risks are priced.
} 
the beginning of period $t$.

In empirical studies, the actual change of spot rate in period $t, \Delta s_{t}$, is often used as a proxy for the expected change, $\mathrm{E}_{t-1}\left(\Delta s_{t}\right)$. In contrast, $\Delta s_{t}$ is not a proxy for any expected variables in our specification. What we are after is the relation between the realized spot rate change and the realized nominal return of a real risk-free (or perfectly indexed) asset.

\section{The Data}

We use three sets of data. The first includes industry stock returns and the three FamaFrench factors, namely, the excess market return, the return on a zero-investment portfolio of $S M B,{ }^{10}$ and the return on a zero-investment portfolio of $H M L,{ }^{11}$ in the United States, the United Kingdom, Japan and Germany. The second set of data are the foreign exchange rates defined as the foreign currency (Yen, British Pound, and German Mark) per U.S. dollar. The third set of data are government CPI inflation measures.

All the U.S. industry returns, the T-bill rates, and the three Fama-French factors are from Kenneth French's web-site ${ }^{12}$ with the sample ranging from July 1926 to December 2000. The UK, German, and Japanese industry returns are from Datastream. For the UK and Germany, total industry returns including dividends are available while only capital gains industry returns are available for Japan. The market returns for the UK, Japan, and Germany are constructed using the total (including dividend) market returns from Datastream, and the SMB and HML factor returns are constructed using raw data from Datastream as well. ${ }^{13}$

\footnotetext{
${ }^{10}$ Longing small firms and short big firms.

${ }^{11}$ Long high book-to-market firms and short low book-to-market firms.

${ }^{12}$ http://mba.tuck.dartmouth.edu/pages/faculty/ken.french/

${ }^{13}$ Xiaoyan Zhang and Kent Daniel kindly provided the SMB and HML data to us.
} 
While the T-bill rates for the UK and Japan are from Datastream, the T-bill rate for Germany is from Bloomberg. The sample period for the UK is from January 1986 to December 1999 (168 monthly observations), for Japan it is from May 1983 to December 1999 (200 monthly observations), and for Germany it is from January 1988 to December 1999 (144 monthly observations).

The change in the foreign exchange rate is calculated from the end of month to the end of month using the daily foreign exchange rate provided by Pacific Foreign Exchange Rate Service. ${ }^{14}$ We also calculated the foreign exchange rate changes from the beginning of the month to the beginning of the month, and the empirical results were virtually unchanged.

Table I provides summary statistics for these three data sets. The market excess return for U.S., UK and Germany is around 1.3-1.4\% per month with a sample standard deviation around $4-5 \%$ per month, but the Japanese market return has much lower mean and slightly higher volatility. The $S M B$ and $H M L$ factors have much smaller mean returns. One-month Treasury Bill rates vary from a high of $0.71 \%$ per month for the UK to a low of thirty basis points in Japan. Official measures of inflation are calculated from CPI data, and monthly average rates are around $0.27 \%, 0.33 \%, 0.19 \%$ and $0.10 \%$ for the U.S., UK, Germany and Japan, respectively.

As is well known in the literature, there is a striking contrast among the volatilities of Treasury Bill rates, CPI inflation rates, and spot rate changes. For example, the sample volatilities of Treasury bill rates are smaller than thirty basis points and CPI inflation rates have sample volatilities smaller than fifty basis points for all four countries. In contrast, spot

\footnotetext{
${ }^{14}$ The foreign exchange rate is from http://pacific.commerce.ubc.ca/xr/.
} 
exchange rate changes for the three currency pairs are all above $3 \%$ per month. This is not surprising if spot rates move not only with actual realized inflation but also with "inflation scares," which could be driven by high frequency economic rumors that materialize only infrequently and thus rarely affect official CPI inflation measures.

\section{Empirical Results}

Our preliminary empirical results for individual country pairs (GM-US, JP-US, and UKUS), first based on the Fama-French three-factor model and then based on the Carhart (1997) four-factor model, are presented in the first two subsections. In the third subsection, we pool the three country pairs in a system regression, which provides a unified framework across all three country pairs and enhances test power as well. In the last subsection, we provide several robustness checks and also examine the relation between our equity-extraced inflation and the official CPI inflation.

\subsection{Results under the Three-Factor Model}

In this subsection, we provide empirical evidence for the relative PPP hypothesis using inflation extracted from equity returns.

First, a time series regression is carried out based on equation (3):

$$
R_{i t}-T B_{t-1}=\alpha_{i}+\beta_{i 1}\left(R_{M t}-T B_{t-1}\right)+\beta_{i 2} R_{S M B, t}+\beta_{i 3} R_{H M L, t}+\eta_{i t}
$$

where $R_{i t}$ is industry $i$ 's portfolio return in period $t$ measured in local currency and $R_{M t}$, $R_{S M B, t}$ and $R_{H M L, t}$ are concurrent country-specific factors also measured in local currency. This procedure is repeated for the U.S., the U.K., Japan and Germany. 
Time-series regressions of the industry portfolio returns are reported in Tables II-V. The adjusted $R^{2}$ varies materially across industries, from as low as $17 \%$ to as high as $88 \%{ }^{15}$ To account for the possibility that the residual term $\eta$ may be serially correlated and heteroscedastic, we always report the Newey-West (1987) adjusted standard errors.

Next cross-sectional regression (4) is computed, with industry returns (minus estimated mispricing) regressed on the beta estimates from the time series regressions. We assume that the cross-sectional residual vector $\epsilon_{t} \equiv\left[\epsilon_{1 t}, \cdots, \epsilon_{n t}\right]$ at time $t$ is uncorrelated with the portfolio's beta estimates, $\hat{\beta}_{k} \equiv\left[\hat{\beta}_{k 1}, \cdots, \hat{\beta}_{k n}\right](k=1,2,3)$, so the estimate of $R_{f t}$ at each period $t$ is unbiased except for the impact from estimation errors in beta. ${ }^{16}$

The estimates for $R_{f t}^{*}$ and $R_{f t}$ are stored for each $t$. We find that both series exhibit extraordinarily high sample volatility, which is probably due to the estimation error in both the time series and the cross-sectional regressions. The sample mean and volatility are reported in Table I. The sample means of $\hat{R}_{f t}$ of the four countries, by construction, are exactly the same as those of the Treasury bill rates. The sample volatility, however, is above $7 \%$ per month, which is a very large number even in comparison with the volatility of spot exchange rate changes. This reflects large measurement errors in our estimates of $R_{f t}$ and is the main reason that we put the estimated nominal rate differentials on the left hand side of the PPP regression as discussed below.

For further comparison, we report summary statistics for the extracted risk-free rate differentials, $\Delta \hat{R}_{f t} \equiv \hat{R}_{f t}^{*}-\hat{R}_{f t}$, official CPI inflation differentials, $\Delta \pi_{C P I} \equiv \pi_{C P I}^{*}-\pi_{C P I}$,

\footnotetext{
${ }^{15}$ The widely varying $R^{2}$ in the time series regression is not an issue so long as it reflects large idiosyncratic noise in some industry portfolio returns, instead of systematic risk remaining in the residual.

${ }^{16}$ Our simulation evidence, not reported for brevity, suggests that our procedure is, in general, quite effective in extracting $R_{f t}$. The second-stage estimate $\hat{R}_{f t}$ is generally unbiased, but $\hat{R}_{f t}$ may be measured with considerable noise. Please also refer to footnote 5 for more discussion of this issue.
} 
and spot exchange rate changes, $\Delta s$, in Table VI. Correlation among the three variables are also provided in the table.

As is well known in the literature, the volatilities of official CPI inflation differentials are too small to be comparable to those of the exchange rate changes: the former are only around one-fifth to around one-tenth of the latter. On the other hand, our extracted risk-free rate is uniformly more volatile than the exchange rate changes with the extracted risk-free rate differential volatilities around two to three times the exchange rate change volatilities. These larger extracted risk-free rate differential volatilities, however, all lie in plausible range, since they should be at least as large as the exchange rate change volatilities if PPP is valid and if in addition, they contain sizable estimation noise. As expected, our extracted risk-free rate differentials are more volatile than the official inflation differentials, which is consistent with the influence of changing expectations absent from the official series and thus resolves the tension between the long-observed grossly larger volatility of exchange rate changes as compared to official inflation differentials.

Despite dramatic differences in standard deviations, the correlation between our extracted and the official inflation differentials are mostly larger than 0.1. The correlations between the official series and the exchange rate changes are positive for the Germany - U.S. pair, but are negative for the Japan - U.S. and the UK - U.S. pairs. In contrast, the correlations between our extracted series and the spot rate changes are all positive and uniformly larger: the correlation is as high as 0.5 for quarterly Germany - U.S. data. 
Finally, we use $\Delta \hat{R}_{f t}$ as a surrogate for $\Delta \pi$ to test the relative PPP hypothesis ${ }^{17}$

$$
\Delta \hat{R}_{f t}=a+b \Delta s+\epsilon
$$

where $H_{0}: a=0$ and $b=1$ under the null hypothesis that relative PPP holds and the mean real rate differential is zero (see equation (7), is tested against the specific alternative $H_{a}: b=0$, i.e., spot rate changes are too volatile to be explained by inflation differentials. ${ }^{18}$ Before carrying out the PPP regression, we first test for unit roots in the foreign exchange rate changes and the extracted nominal risk-free rate differentials. Both the Augmented Dickey-Fuller and the Phillips-Perron tests reject the null of unit roots.

Tables VII reports relative PPP regression results for three different horizons: the monthly horizon, the bi-monthly horizon, and the quarterly horizon. Both the bi-monthly and the quarterly horizons use non-overlapping observations. In order to adjust for the impact of heteroscedasticity and serial correlation, Newey-West adjusted standard errors are reported in the Table.

At the monthly frequency, the coefficients for the contemporaneous exchange rate changes are significantly different from zero at the $5 \%$ but not significantly different from one for the Yen-Dollar and the Mark-Dollar pair.

At the bi-monthly and quarterly frequencies, the results are broadly consistent with the

\footnotetext{
${ }^{17}$ For comparison, we also used the CPI inflation differential as the dependent variable in the relative PPP regression. In this case, the intercepts are all significantly different from zero while slope coefficients are all close to zero and either not statistically significant or have the wrong sign. The adjusted $R^{2}$ are close to zero or negative. The detailed results are omitted from the paper for brevity and are available upon request.

${ }^{18}$ Note that the relative PPP hypothesis is tested against a specific alternative. The presence of a foreign exchange premium, as documented in some empirical studies, is also inconsistent with relative PPP in the sense that under this alternative $b \neq 1$. However, we do not know what value of $b$ is implied by the presence of a foreign exchange premium, so a failure to reject the null of $b=1$ may not shed much light on this question.
} 
PPP hypothesis for all three pairs of currencies. The intercepts in all regressions are not significantly different from zero. The slopes are all above 0.6 and significantly different from zero but not significantly different from one at the bi-monthly frequency. At the quarterly frequency, the UK-US pair has a slope estimate significantly different from zero at $10 \%$ but not from one at the same significance level. The adjusted $R^{2} \mathrm{~s}$, though not high, are not very different from our simulation results (omitted from the paper for brevity), especially for the Mark-Dollar pair. The small $R^{2}$ is consistent with our observation that there are large measurement errors contained in our nominal rate estimates.

For each individual country pair, an $F$ test is carried out to test the joint hypothesis: $a=0$ and $b=1 \cdot{ }^{19}$ Consistent with the individual $t$-tests, the test fails to reject the null that relative PPP holds in seven out of nine cases. It is strongly rejected with a $p$-value well below $1 \%$ for the Pound-Dollar pair at the monthly frequency and also rejected at the $10 \%$ significance level with a $p$-value around $7 \%$ for the Yen-Dollar pair at the monthly frequency, but all the other seven tests have quite large $p$-values and fail to reject the null at a comfortable margin.

In contrast to the existing empirical results in the literature on testing the short run PPP hypothesis, our point estimates are quite close to one in magnitude and generally significantly different from zero but not from one. Since the strongest evidence in favor of the relative PPP comes from regressions using bi-monthly and quarterly data with relatively fewer observations, we also carry out a bootstrap simulation and report the point estimates and the bootstrapped standard errors in the same table. ${ }^{20}$ Evident in both the point esti-

\footnotetext{
${ }^{19} \mathrm{~A}$ joint test across all three country pairs is performed and reported in Section 3.3.

${ }^{20}$ In the bootstrap procedure, we randomly draw data from the original sample with replacement and
} 
mates and the standard errors, there is virtually no difference between the bootstrap results and the OLS estimates and the Newey-West standard errors: in the Pound-Dollar pair, the bootstrap standard errors are slightly larger and thus push the slope estimate from marginal significance to insignificance at the quarterly frequency, while the standard errors in the other two country pairs are smaller and thus strengthen our earlier results.

Finally, we carry out the PPP test for other cross currency pairs, whose results are not reported for brevity. In summary, the PPP regression estimates of the slope coefficient are similar to those found in the results reported for currency pairs involving the US dollar but they are not statistically significant. It is worth mentioning here that the efficacy of these PPP tests depends critically on how well the Fama-French three factor model describes the real stock returns and spans the real impact of inflation. We believe, however, that real factors left over in our estimates are more likely to bias against the PPP hypothesis, because there is no a priori theory or economic intuition that the spot rate changes move one-to-one with real factor differentials across different countries. To the extent that real factors may affect different economies at different times and with different significance, the spot rate changes are unlikely to move with the real factor differentials in a one-to-one relation across almost all country pairs that we have examined. The Fama-French three-factor model seems to fit the U.S. data quite well and has been subjected to intensive study; other countries, however, have not been scrutinized as thoroughly. Therefore, the stronger results for currency pairs involving the US dollar are likely due to the better fit of the Fama-French three-factor

carry out the regression using the new sample. The procedure is repeated 1000 times, and the mean and the standard deviation across these 1000 estimates are reported as the bootstrap point estimate and the bootstrap standard error in the table. See Efron and Tibshirani (1994) for an excellent description of the bootstrap procedure. 
model for US portfolio returns.

\subsection{Results under the Four-Factor Model}

Some scholars have argued that the three factor model of Fama and French does not adequately capture the time series variation in stock returns and a fourth real factor, Momentum, explains a significant portion of stock returns. ${ }^{21}$ We only have the Momentum factor for the U.S., so we repeated analysis by fitting a four-factor model to U.S. industry portfolios. For brevity, we omit the time-series regression results and only report the PPP regression results in Table VIII.

The results support the PPP hypothesis even more strongly. In particular, the slope coefficients become closer to one with smaller standard errors, and the overall fit as measured by $R^{2}$ s also improves at all frequencies.

The results remain virtually unchanged for the Mark-Dollar pair for which the original results in Table VIII were already quite strong. The slope estimates for the Yen-Dollar and the Pound-Dollar pairs improve to, respectively, 0.87 and 0.74 at the bi-monthly frequency, and to 0.90 and 0.76 at the quarterly frequency. Although the point estimate $\hat{b}$ for the YenDollar pair at the monthly frequency remains at the mid way (0.58) between zero and one, the joint $F$-test now has a $p$-value of around $14 \%$ as compared to $7 \%$ before and fails to reject the null hypothesis at $10 \%$ significance level. The point estimate $\hat{b}$ for the Pound-Dollar pair at the monthly frequency remains low at only 0.33 and remains significantly different from one, but it is now also different from zero at a $10 \%$ significance level. Similar to the earlier

\footnotetext{
${ }^{21}$ Carhart (1997) uses a 4-factor model to evaluate mutual fund performance and argues that the 4-factor model noticeably reduces the average pricing errors relative to both the CAPM and the 3 -factor model.
} 
observation, the bootstrap results are virtually the same as those of the OLS regressions.

The above results confirm our conjecture that real factors left over in our estimates are more likely to bias against the finding of PPP relation, and a better factor model, by more effectively purging real effects of the nominal equity returns, leads to cleaner and better (less noisy) estimates of the "ex-post" nominal risk-free rate, and thus a sharper test of the PPP relation in the last step.

\subsection{Results from Pooled Regressions}

Although our individual currency-pair results taken together are broadly in favor of the relative PPP hypothesis, one important currency pair, namely the Pound-Dollar pair, consistently rejects the PPP at the monthly frequency. A joint test statistic across all three country pairs may help us interpret the results in a more unified way. To serve this purpose, we pool all three country pairs in a system of equations. The additional advantage of a pooled regression is its enhanced power by using information from other cross country pairs.

First, an unconstrained seemingly unrelated regression (SUR) is computed:

$$
\left[\begin{array}{c}
R_{f t, J P}^{*}-R_{f t, U S} \\
R_{f t, U K}^{*}-R_{f t, U S} \\
R_{f t, G e r}^{*}-R_{f t, U S}
\end{array}\right]=\left[\begin{array}{c}
a_{1} \\
a_{2} \\
a_{3}
\end{array}\right]+\left[\begin{array}{ccc}
\Delta s_{t, J P} & 0 & 0 \\
0 & \Delta s_{t, U K} & 0 \\
0 & 0 & \Delta s_{t, G e r}
\end{array}\right]\left[\begin{array}{c}
b_{1} \\
b_{2} \\
b_{3}
\end{array}\right]+\epsilon_{t} .
$$

Table IX reports the SUR feasible generalized least square (FGLS) regression results in Panel A for the monthly, bi-monthly and the quarterly horizon where the contemporaneous correlations between different country pairs are taken into account not only in the standard errors but also in the point estimates. ${ }^{22}$ Panel B of the table reports the $F$-statistics and the

\footnotetext{
${ }^{22}$ Cochrane (2001) argues that the GLS procedure is more efficient only if the error covariance matrix
} 
corresponding $p$-values for joint tests across equations. There are five null hypothesis tests in the table: (1) the intercepts are zero for all equations; (2) the slope coefficients are zero for all equations; (3) the slope coefficients are the same across all equations; (4) the slope coefficients are all equal to one; and (5) the intercepts are zero and the slopes are one for all country pairs.

Comparing the results in Panel A of Table IX with those in Tables VII and VIII, we note that the FGLS slope coefficients, although still significant for the Yen-Dollar (at 10\% level) and Mark-Dollar (at 5\% level) pairs at the monthly horizon, are uniformly smaller in magnitude and closer to zero than to one when system of equations are used. The results for the bi-monthly horizon, however, are much more encouraging. Although the FGLS point estimates for the three slopes are also smaller than those reported in Tables VII and VIII, they are mostly above 0.5 and statistically different from zero but not from one except for the Pound-Dollar pair under the three-factor model. The result for Mark-Dollar pair remains the strongest support for the relative PPP where the slope estimate is around 0.97 under the three-factor and 0.94 under the four-factor model. The results for the quarterly horizon show some slight improvement over the bimonthly results and are also in favor of the relative PPP hypothesis as illustrated by the individual $t$-ratios for the slope estimates.

The joint $F$ tests reported in Panel B of Table IX lend strong support for the relative PPP hypothesis at the bi-monthly and quarterly horizons as well. The $p$-values for the hypothesis that intercepts are zero for all equations are above 0.9 at all three horizons so

is correctly modeled and the regression is perfectly specified. Otherwise, the GLS is less robust than OLS especially when the variance-covariance matrix has to be estimated. In particular, the FGLS can put unreasonable weight on slightly misspecified area of the model and give misleading point estimates. The OLS estimates under SUR are the same as those under individual country-pair regressions reported in Tables VI and VII. 
that the null is accepted. The null hypothesis that the slopes are all zero is rejected at $5 \%$ or better significance level. One can easily accept the null that the slopes are all equal across the three equations, and the test fails to reject the null that the slopes are all equal to one as well except for the monthly horizon. Finally, the null that the intercepts are all zero and the slopes are all one is also accepted at both the bi-monthly and the quarterly horizons.

Since the hypotheses that the intercept, $a_{i}$, and the slope, $b_{i}$, are the same across equations are not rejected, these constraints are imposed in the following regression:

$$
\left[\begin{array}{c}
R_{f t, J P}^{*}-R_{f t, U S} \\
R_{f t, U K}^{*}-R_{f t, U S} \\
R_{f t, G e r}^{*}-R_{f t, U S}
\end{array}\right]=a+\left[\begin{array}{c}
\Delta s_{t, J P} \\
\Delta s_{t, U K} \\
\Delta s_{t, G e r}
\end{array}\right] b+\epsilon_{t} .
$$

Imposition of the constraint provides a more precise estimate of the coefficients and more powerful tests of the hypothesis if the constraints are true.

The results are reported in Table X, where Panel A contains results using the FamaFrench three-factor model while Panel B contains results when a four-factor model is applied to the U.S. data. The constrained intercept estimate, $\hat{a}$, is not significant, and the constrained slope estimate, $\hat{b}$, is significantly different from zero at all three horizons. Although $\hat{b}$ at the monthly horizon remains significantly different from one, $\hat{b}$ 's at bi-monthly and quarterly frequencies are quite close to one in magnitude and statistically insignificantly different from one. For example, $\hat{b}$ is above 0.9 at quarterly horizon under both the three-factor and the four-factor models. The joint $F$-test for $H_{0}: a=0, b=1$ is also reported. Consistent with the implications from the individual $t$-ratios, the null hypothesis is strongly rejected at the monthly horizon but is comfortably accepted at the bi-monthly and quarterly frequency. 
Although the Newey-West standard errors adjust for heteroscedasticity and serial autocorrelation, they may still be under-estimated due to the possible contemporaneous covariation among the three country pairs. To the extent that the three country pairs are perfectly contemporaneously correlated, the standard errors are under-estimated by $\sqrt{3}$. A bootstrap simulation is carried out to obtain the contemporaneous-covariation-adjusted standard errors.

The system of equations have a total number of $n=512$ observations across the three currency-pairs. Instead of randomly drawing 512 observations from the original sample with replacement, only 144 observations, which is the sample size of the Mark-Dollar pair, are drawn from the original sample with replacement. The estimation is then carried out using the new sample. This procedure is repeated 2000 times, and the average and the standard deviation across these 2000 estimates are reported as the bootstrap estimate and standard errors in the table. The reported standard errors thus represent upper bounds. Note that the standard errors are substantially larger than the Newey-West ones, but the point estimates are very close to the OLS estimates. Despite the much larger standard errors, the null hypothesis $b=1$ is still not rejected at the bi-monthly and quarterly horizons while the null $b=0$ is rejected at the $5 \%$ significance level for all three horizons.

\subsection{Robustness Checks}

\subsubsection{Are the results driven by real effects of inflation?}

In our model (2), there is an implicit assumption that either the inflation does not have real effects or its real effects are spanned by the Fama-French three factors. Boudoukh, Richardson and Whitelaw (1994) argue that expected inflation may be correlated with future 
production and thus affect real stock returns. They find some interesting inflation beta patterns across industries in a regression without any other factors, but none of their beta estimates are statistically significant. We also examine their conjecture by augmenting our factor models with an additional expected inflation factor. The results are omitted from the paper for brevity. In general, we find that most of the expected inflation betas are statistically insignificant, and the PPP test results improve marginally.

\subsubsection{Are the results driven by a world factor?}

We did not include a world factor in the asset pricing model for the reasons given in Section 1.1. This means that the factor generating model could possibly be mis-specified in the sense that the residuals $\eta_{i t}$ from the time-series regressions in (3) or our estimates of $R_{f t}$ contain a missing world factor. The same world factor, expressed in units of foreign currencies, could also be contained in the corresponding estimates of $R_{f t}^{*}$. This suggests the possibility that our PPP tests might merely be detecting a much weaker phenomenon; viz., the law of one price holds for the world factor. To check on this possibility, we performed the following procedure.

The Morgan Stanley Composite Index (MSCI), ${ }^{23}$ is a widely-used proxy for a world factor. We regressed the residuals from the time series industry returns and our estimates of $R_{f t}$ on MSCI returns. The results (not reported here for brevity) reveal that neither the residuals from time series regressions nor the estimates of $R_{f t}$ for any country are related to the MSCI returns.

\footnotetext{
${ }^{23}$ The data is provided by the MSCI web-site http://www.msci.com/
} 


\subsubsection{Are the results driven by other missing factors?}

Even though neither the world factor nor the real effect of inflation is behind the supportive evidence on the short run PPP relation, it is still possible that our extracted series represents a factor other than inflation and the differentials of this mysterious factor across all three country pairs happen to move one-to-one with the corresponding foreign exchange rate changes.

Since $\hat{R}_{f t}$ is estimated as the intercept of the cross-sectional regression in the FamaMacBeth approach, $\hat{R}_{f t}$ moves one-to-one with all industry portfolio returns by construction. In our view, the most natural interpretation of $\hat{R}_{f t}$ in the Fama-MacBeth regression is the "ex-post" nominal risk-free rate, which is then used as a surrogate for pure price inflation. If $\hat{R}_{f t}$ measures a non-inflation factor, then it must be systematic and influence all industries equally. If such a factor existed, then it should be subsumed in the market return factor. To see this formally, imagine that a factor $\theta_{t}$ affects returns of all industries equally and the return generating process is described by:

$$
R_{i t}=\theta_{t}+R_{f t}+\beta_{i}\left(R_{M t}-R_{f t}\right)+\epsilon_{i t} .
$$

Take a weighted sum, where weights are market value weights, across all $i$ to obtain:

$$
\sum_{i} w_{i} R_{i t}=\theta_{t}+R_{f t}+\left(R_{M t}-R_{f t}\right) \sum_{i} w_{i} \beta_{i}+\sum_{i} w_{i} \epsilon_{i t} .
$$

By definition $\sum_{i} w_{i} R_{i t}=R_{M t}$ and $\sum_{i} w_{i} \beta_{i}=1$. For a large number of stocks or industry portfolios, $\sum_{i} w_{i} \epsilon_{i t} \simeq 0$ which implies that

$$
R_{M t} \simeq \theta_{t}+R_{f t}+\left(R_{M t}-R_{f t}\right)
$$


or that $\theta_{t} \simeq 0$. Therefore, it is unlikely that $\hat{R}_{f t}$ captures a systematic risk factor after controlling for the market factor in the regression. ${ }^{24}$

Since our estimates of the "ex-post" nominal risk-free rates include the real risk-free rates, one might also argue that it is the real interest rate differential, rather than the pure price inflation differential, that is correlated with foreign exchange rate changes. Even if one could conceive of a model in which such a link can be established, it will be difficult to argue on a priori theoretical grounds that the volatility of real interest rate differentials could be of the same order of magnitude as the empirical estimates of the volatility of the nominal exchange rate changes.

Finally, it is unlikely that the extracted factor, if it measures something other than inflation and real risk-free rate, satisfies relative PPP so well. We further examine this issue in the next subsection by providing evidence that $\hat{R}_{f t}$ and the official CPI inflation measure have a long run cointegration relation (Table XI) even though their short run correlation is weak (Table VI).

\subsubsection{How well does $\hat{R}_{f t}$ track the official inflation measure?}

We examine what relation, if any, exists between our extracted nominal risk-free rates and official inflation estimates. A direct comparison is difficult for five reasons. One, our extracted variables $\hat{R}_{f t}$ contain both pure price inflation and real interest rates. That's why the sample means of our extracted variables are higher than those of CPI inflation measures, $\pi_{C P I}$, as reported in Table I. Two, our $\hat{R}_{f t}=R_{f t}+\epsilon_{t}$ 's are estimated with considerable

\footnotetext{
${ }^{24}$ Because of this argument, it is unlikely that $\hat{R}_{f t}$ contains a foreign exchange rate factor. The existing empirical evidence of whether foreign exchange risk affects expected returns is mixed. The foreign exchange rate is found to be a significant factor only for a subset of firms and its beta is rarely close to one. Karolyi and Stulz (2003) provide a survey of the empirical findings.
} 
noise, as illustrated by their large sample volatilities. Three, the CPI is constructed from commodity prices sampled throughout the month, and it provides a closer measure of inflation from mid-month to mid-month while the extracted risk-free rate is the end-of-month measure, leading to some mis-matching of time period. Four, inflation measures using CPI data would include not only pure price inflation but also effects of relative price changes. This reason is one of the motivations for constructing a pure inflation measure. Finally, as we argued earlier, our extracted price inflation measure is responsive to news and changes in expectations about future prices whereas official indices may be sticky.

Nevertheless, we expect some association between $\hat{R}_{f t}$ and $\pi_{C P I}$ in the long run when the temporary swings in short run inflation measure cancel one another out and the smooth official series becomes a better measure of realized long run inflation. To the extent that they both measure inflation well over the long run, the price level implied by the two series should be cointegrated. ${ }^{25}$

To examine this hypothesis, we first create a hypothetical price index for $\hat{R}_{f t}, P_{R_{f}, t}$, by setting the initial value to one $\left(P_{R_{f}, 0}=1\right)$ :

$$
P_{R_{f}, t}=P_{R_{f}, t-1}\left(1+\hat{R}_{f_{t}}\right)
$$

The CPI is similarly constructed:

$$
P_{C P I, t}=P_{C P I, t-1}\left(1+\pi_{C P I}\right)
$$

which is equivalent to re-setting the official CPI to one at the beginning of the sample.

\footnotetext{
${ }^{25}$ We are grateful to the editor, Ben Bernanke, for suggesting that we test for cointegration between our extracted series and the official CPI series.
} 
The Augmented Dickey-Fuller (ADF) test cannot reject the null of unit root for all $P_{C P I}$ series across the 4 countries and for $P_{R_{f}}$ in GM, UK and US at $5 \%$ level, but it does reject the null of unit root for the Japanese $P_{R_{f}}(p$-value=0.045). On the other hand, the ADF fails to reject the null of unit root in all logged price indices. In other words, all price level series appear to be non-stationary.

Table XI reports the result of the Johansen cointegration test and the Johansen Maximum Likelihood estimate of the cointegrating vector, with the coefficient of $P_{R_{f}}$ normalized to unity. The Johansen test rejects the null of no cointegration between $P_{R_{f}}$ and the CPI across all four countries, indicating that there is a long run cointegration relation between $P_{R_{f}}$ and CPI. The cointegration regression yields highly significant cointegrating parameters in three currencies (GM, UK and US). Although the cointegrating coefficient need not equal 1.0 for reasons mentioned above, it is actually not significantly different from 1.0 for all four countries. ${ }^{26}$

\section{Concluding Remarks}

Our paper makes two contributions. First, we provide a novel application of the FamaMacBeth approach to extract the "ex-post" nominal risk-free return from stock returns, which is then used as a surrogate for realized pure price inflation. This is done by exploiting the fact that the intercept in the second stage Fama-MacBeth procedure measures the nominal risk-free rate. Instead of focusing on the sample mean of this series as is often done in the asset pricing literature, we take advantage of its time series behavior and use it as a

\footnotetext{
${ }^{26}$ The same analysis is carried out using logged price indices. The results are more or less similar to those obtained when the price indices are directly used.
} 
surrogate for the unobservable inflation series.

Second, we provide compelling evidence that relative purchasing power parity holds quite well in the short run when inflation is extracted from stock prices. Our results complement the current consensus that PPP holds in the long run. This is in sharp contrast to the poor performance of short-term PPP documented in the extensive literature surveyed in Rogoff (1996) where inflation measures were based on official series such as the CPI.

The support for PPP using our extracted inflation measures suggests that the price level affecting financial markets is much more volatile than official price indices computed from the prices of goods and services. It is natural to ponder why monetary shocks might affect the financial market and the goods and services market in such different ways. One possibility is that financial asset prices are affected by "news" and "perceptions" which may be temporary in nature and may not materialize in the future, while prices of consumer goods change gradually and infrequently only with clear and compelling evidence of a long run permanent event. In addition, prices in financial markets are usually fully flexible and determined by continuous trading of investors, whereas prices of consumer goods are often posted before the transaction date; it can be costly to change a posted price despite the small "menu cost" as argued in Mankiw (1985).

Even though the short run correlation between our extracted series and official CPI inflation is weak, we find strong evidence that our extracted price index and the CPI are cointegrated.

Our series reflects high volatility of inflation in the short run, which is not well captured by official CPI inflation. If the inflation reflected in financial markets is much more volatile 
than official inflation, there is no need to rely on some form of exchange rate "overshooting" (Dornbusch ,1976), to explain exchange rate volatility, particularly given that implications of overshooting do not seem to be supported by empirical evidence (Rogoff, 2002). 


\section{Table I}

\section{Data Summary Statistics}

This table reports sample mean and sample volatility for the three Fama-French factor returns for the U.S., UK, Germany and Japan. The sample mean and volatility for the change in the foreign exchange rate are also reported. The sample period for the U.S. and Japan is from May 1983 to December 1999, for UK is from January 1986 to December 1999, and for Germany is from January 1988 to December 1999. The numbers are percent per month.

\begin{tabular}{|c|c|c|}
\hline Variable & Mean & Standard Deviation \\
\hline US Market & 1.36 & 4.24 \\
\hline US SMB & -0.20 & 2.67 \\
\hline US HML & 0.15 & 2.72 \\
\hline US Tbill & 0.48 & 0.16 \\
\hline US CPI Inflation & 0.27 & 0.20 \\
\hline US Extracted Risk-free Rate & 0.48 & 7.15 \\
\hline UK Market & 1.39 & 4.83 \\
\hline UK SMB & 0.05 & 4.11 \\
\hline UK HML & 0.26 & 2.55 \\
\hline UK Tbill & 0.71 & 0.26 \\
\hline UK £- US \$ & -0.07 & 3.14 \\
\hline UK CPI Inflation & 0.33 & 0.47 \\
\hline UK Extracted Risk-free Rate & 0.71 & 8.22 \\
\hline German Market & 1.34 & 5.15 \\
\hline German SMB & -0.44 & 4.41 \\
\hline German HML & 0.28 & 3.26 \\
\hline German Tbill & 0.44 & 0.17 \\
\hline German DM - US \$ & 0.15 & 3.10 \\
\hline German CPI Inflation & 0.19 & 0.26 \\
\hline German Extracted Risk-free Rate & 0.44 & 7.37 \\
\hline Japan Market & 0.75 & 5.92 \\
\hline Japan SMB & 0.03 & 3.34 \\
\hline Japan HML & 0.13 & 3.07 \\
\hline Japan Tbill & 0.30 & 0.21 \\
\hline Japanese Yen - US \$ & -0.42 & 3.52 \\
\hline Japanese CPI Inflation & 0.10 & 0.47 \\
\hline Japanese Extracted Risk-free Rate & 0.30 & 8.73 \\
\hline
\end{tabular}




\title{
Table II
}

Time Series Regressions of Excess Industry Returns on the Three Fama-French Factors (U.S.)

\begin{abstract}
This table reports the regression results of excess industry portfolio returns on the three Fama-French factors for the U.S. with sample period from January 1986 to December 1999. The Newey-West adjusted standard errors are reported in parentheses to the right of the coefficient estimates.
\end{abstract}

\begin{tabular}{|c|c|c|c|c|c|c|c|c|c|}
\hline Industry & \multicolumn{2}{|c|}{ Constant } & \multicolumn{2}{|c|}{$R_{m}-$ Tbill } & \multicolumn{2}{|c|}{$R_{S M B}$} & \multicolumn{2}{|c|}{$\overline{R_{H M L}}$} & Adj. $R^{2}$ \\
\hline Food & -0.017 & $(0.27)$ & 0.967 & $(0.06)$ & -0.444 & $(0.12)$ & 0.044 & $(0.17)$ & 0.633 \\
\hline Beer & 0.103 & $(0.27)$ & 0.798 & $(0.08)$ & -0.360 & $(0.11)$ & -0.268 & $(0.16)$ & 0.500 \\
\hline Smoke & 0.176 & $(0.54)$ & 0.926 & $(0.11)$ & -0.195 & $(0.23)$ & 0.154 & $(0.33)$ & 0.271 \\
\hline Games & 0.099 & $(0.31)$ & 1.174 & $(0.07)$ & 0.336 & $(0.17)$ & -0.103 & $(0.22)$ & 0.699 \\
\hline Books & -0.216 & $(0.19)$ & 1.088 & $(0.06)$ & 0.087 & $(0.07)$ & 0.196 & $(0.12)$ & 0.757 \\
\hline Household & 0.198 & $(0.14)$ & 1.018 & $(0.04)$ & -0.389 & $(0.06)$ & -0.144 & $(0.07)$ & 0.851 \\
\hline Apparel & -0.872 & $(0.33)$ & 1.180 & $(0.08)$ & 0.462 & $(0.12)$ & 0.232 & $(0.22)$ & 0.648 \\
\hline Health & 0.247 & $(0.24)$ & 0.902 & $(0.06)$ & -0.404 & $(0.09)$ & -0.456 & $(0.18)$ & 0.710 \\
\hline Chemicals & -0.164 & $(0.20)$ & 1.129 & $(0.06)$ & 0.051 & $(0.07)$ & 0.424 & $(0.17)$ & 0.685 \\
\hline Textiles & -0.582 & $(0.36)$ & 1.116 & $(0.08)$ & 0.854 & $(0.12)$ & 0.681 & $(0.18)$ & 0.615 \\
\hline Construction & -0.324 & $(0.20)$ & 1.192 & $(0.04)$ & 0.245 & $(0.07)$ & 0.307 & $(0.09)$ & 0.825 \\
\hline Steel & -0.355 & $(0.30)$ & 1.149 & $(0.07)$ & 0.533 & $(0.11)$ & 0.407 & $(0.15)$ & 0.610 \\
\hline Fabricated Products & -0.291 & $(0.25)$ & 1.163 & $(0.04)$ & 0.626 & $(0.08)$ & 0.286 & $(0.10)$ & 0.776 \\
\hline Electronic Equipment & 0.195 & $(0.34)$ & 1.076 & $(0.06)$ & 0.538 & $(0.12)$ & -0.501 & $(0.25)$ & 0.761 \\
\hline Autos & -0.296 & $(0.26)$ & 1.262 & $(0.05)$ & 0.216 & $(0.08)$ & 0.716 & $(0.13)$ & 0.708 \\
\hline Carry & -0.300 & $(0.28)$ & 1.147 & $(0.09)$ & 0.081 & $(0.10)$ & 0.339 & $(0.17)$ & 0.640 \\
\hline Mines & -0.355 & $(0.43)$ & 0.795 & $(0.11)$ & 0.790 & $(0.16)$ & 0.371 & $(0.19)$ & 0.308 \\
\hline Coal & -0.712 & $(0.36)$ & 0.974 & $(0.08)$ & 0.634 & $(0.16)$ & 0.559 & $(0.20)$ & 0.455 \\
\hline Oil & -0.035 & $(0.28)$ & 0.854 & $(0.07)$ & 0.051 & $(0.13)$ & 0.540 & $(0.12)$ & 0.447 \\
\hline Utilities & -0.165 & $(0.22)$ & 0.611 & $(0.06)$ & -0.284 & $(0.11)$ & 0.580 & $(0.14)$ & 0.462 \\
\hline Telecommunication & 0.437 & $(0.29)$ & 0.928 & $(0.07)$ & -0.156 & $(0.09)$ & -0.022 & $(0.13)$ & 0.627 \\
\hline Services & 0.638 & $(0.18)$ & 1.004 & $(0.05)$ & 0.262 & $(0.10)$ & -0.882 & $(0.13)$ & 0.848 \\
\hline Business Equipment & 0.266 & $(0.31)$ & 0.985 & $(0.07)$ & 0.305 & $(0.14)$ & -0.565 & $(0.19)$ & 0.696 \\
\hline Paper & -0.273 & $(0.18)$ & 1.088 & $(0.06)$ & 0.105 & $(0.09)$ & 0.267 & $(0.16)$ & 0.682 \\
\hline Trans & -0.507 & $(0.24)$ & 1.162 & $(0.06)$ & 0.325 & $(0.10)$ & 0.496 & $(0.10)$ & 0.702 \\
\hline Wholesale & -0.317 & $(0.17)$ & 1.025 & $(0.05)$ & 0.426 & $(0.06)$ & 0.016 & (0.11) & 0.870 \\
\hline Retail & 0.200 & $(0.23)$ & 1.085 & (0.07) & 0.163 & $(0.08)$ & -0.168 & (0.10) & 0.746 \\
\hline Meals & -0.302 & $(0.24)$ & 1.079 & $(0.06)$ & 0.284 & $(0.12)$ & 0.091 & $(0.14)$ & 0.735 \\
\hline Finance & -0.232 & $(0.14)$ & 1.159 & $(0.05)$ & -0.160 & $(0.07)$ & 0.474 & (0.07) & 0.881 \\
\hline Other & -0.775 & $(0.32)$ & 1.199 & $(0.06)$ & 0.258 & $(0.09)$ & 0.265 & $(0.21)$ & 0.696 \\
\hline
\end{tabular}


Table III

Time Series Regressions of Excess Industrial Returns on the Three Fama-French Factors

$$
\text { (U.K.) }
$$

This table reports the regression results of excess industry portfolio returns on the three Fama-French factors for the U.K. with sample period from January 1986 to December 1999. The Newey-West adjusted standard errors are reported in parentheses to the right of the coefficient estimates.

\begin{tabular}{|c|c|c|c|c|c|c|c|c|c|}
\hline Industry & \multicolumn{2}{|c|}{ Constant } & \multicolumn{2}{|c|}{$R_{m}-$ Tbill } & \multicolumn{2}{|c|}{$R_{S M B}$} & \multicolumn{2}{|c|}{$R_{H M L}$} & Adj. $R^{2}$ \\
\hline Mining & 0.166 & $(0.42)$ & 1.183 & $(0.12)$ & 0.212 & $(0.20)$ & 0.187 & $(0.27)$ & 0.426 \\
\hline Oil \& Gas & 0.229 & $(0.28)$ & 0.878 & $(0.09)$ & -0.028 & $(0.08)$ & 0.507 & $(0.18)$ & 0.518 \\
\hline Chemicals & -0.316 & $(0.32)$ & 1.060 & $(0.06)$ & 0.111 & $(0.09)$ & -0.168 & $(0.18)$ & 0.631 \\
\hline Construction & -0.749 & $(0.28)$ & 1.270 & $(0.06)$ & 0.141 & $(0.08)$ & 0.543 & $(0.13)$ & 0.718 \\
\hline Forestry \& Paper & -0.024 & $(0.54)$ & 1.171 & $(0.13)$ & 0.392 & $(0.19)$ & 0.073 & $(0.30)$ & 0.303 \\
\hline Steel & -0.008 & $(0.45)$ & 1.300 & $(0.10)$ & 0.308 & $(0.15)$ & 0.507 & $(0.21)$ & 0.402 \\
\hline Aerospace \& Defense & -0.377 & $(0.38)$ & 1.117 & $(0.10)$ & 0.164 & $(0.16)$ & -0.046 & $(0.22)$ & 0.526 \\
\hline Diversified Industrials & -0.610 & $(0.27)$ & 1.076 & $(0.05)$ & 0.050 & $(0.06)$ & -0.042 & $(0.15)$ & 0.660 \\
\hline Electronic Equipment & 0.240 & $(0.35)$ & 1.091 & $(0.13)$ & 0.449 & $(0.24)$ & -0.497 & $(0.27)$ & 0.529 \\
\hline Engineering Machinery & -0.346 & $(0.28)$ & 1.223 & $(0.07)$ & 0.291 & $(0.09)$ & -0.005 & $(0.17)$ & 0.691 \\
\hline Autos & 0.084 & $(0.38)$ & 1.256 & $(0.09)$ & 0.142 & $(0.11)$ & -0.106 & $(0.19)$ & 0.568 \\
\hline Textiles & -1.260 & $(0.41)$ & 1.202 & $(0.09)$ & 0.284 & $(0.14)$ & 0.222 & $(0.22)$ & 0.640 \\
\hline Beverages & -0.128 & $(0.25)$ & 0.928 & $(0.07)$ & -0.226 & $(0.11)$ & -0.242 & $(0.14)$ & 0.685 \\
\hline Food & -0.183 & $(0.23)$ & 0.810 & $(0.07)$ & -0.047 & $(0.11)$ & -0.092 & $(0.17)$ & 0.651 \\
\hline Health & -0.294 & $(0.21)$ & 0.943 & $(0.05)$ & 0.183 & $(0.06)$ & -0.348 & $(0.16)$ & 0.670 \\
\hline Pack & -0.347 & $(0.34)$ & 1.128 & $(0.07)$ & 0.178 & $(0.12)$ & -0.070 & $(0.17)$ & 0.558 \\
\hline Personal Care & -0.323 & $(0.36)$ & 0.826 & $(0.08)$ & -0.203 & $(0.10)$ & 0.014 & $(0.19)$ & 0.389 \\
\hline Pharmaceutical \& Biotechnology & 0.782 & $(0.30)$ & 0.840 & $(0.08)$ & -0.097 & $(0.09)$ & -0.901 & $(0.17)$ & 0.573 \\
\hline Tobacco & 0.346 & $(0.47)$ & 0.776 & $(0.16)$ & -0.308 & $(0.17)$ & 0.214 & $(0.25)$ & 0.326 \\
\hline Dist. & -0.409 & $(0.28)$ & 1.182 & $(0.06)$ & 0.307 & $(0.08)$ & 0.015 & $(0.11)$ & 0.693 \\
\hline General Retailers & -0.516 & $(0.24)$ & 0.904 & $(0.05)$ & -0.174 & $(0.08)$ & 0.209 & $(0.14)$ & 0.664 \\
\hline Entertainment \& Hotels & -0.312 & $(0.28)$ & 1.178 & $(0.08)$ & 0.075 & $(0.08)$ & 0.316 & $(0.11)$ & 0.743 \\
\hline Media & 0.064 & $(0.22)$ & 1.272 & $(0.06)$ & 0.371 & $(0.10)$ & -0.184 & $(0.10)$ & 0.758 \\
\hline Restaurants \& Pubs & -0.144 & $(0.26)$ & 0.819 & $(0.08)$ & -0.154 & $(0.06)$ & 0.269 & $(0.11)$ & 0.620 \\
\hline Support & -0.096 & $(0.20)$ & 1.085 & $(0.05)$ & 0.375 & $(0.07)$ & -0.138 & $(0.08)$ & 0.725 \\
\hline Transport & -0.261 & $(0.25)$ & 1.023 & $(0.05)$ & 0.058 & $(0.07)$ & 0.200 & $(0.15)$ & 0.732 \\
\hline Food \& Drug Retailers & -0.225 & $(0.33)$ & 0.684 & $(0.06)$ & -0.126 & $(0.09)$ & 0.186 & $(0.18)$ & 0.385 \\
\hline Telecom Services & 0.605 & $(0.38)$ & 0.856 & $(0.09)$ & -0.134 & $(0.11)$ & -0.200 & $(0.17)$ & 0.498 \\
\hline Banks & 0.440 & $(0.25)$ & 1.117 & $(0.08)$ & -0.346 & $(0.08)$ & 0.436 & $(0.19)$ & 0.720 \\
\hline Insurance & -0.387 & $(0.25)$ & 1.073 & $(0.07)$ & -0.166 & $(0.08)$ & 0.181 & $(0.11)$ & 0.679 \\
\hline Life Assurance & 0.479 & $(0.28)$ & 0.925 & $(0.06)$ & -0.122 & $(0.07)$ & 0.067 & $(0.14)$ & 0.557 \\
\hline Investment Firms & -0.100 & $(0.15)$ & 1.066 & $(0.05)$ & 0.165 & $(0.06)$ & 0.031 & $(0.07)$ & 0.870 \\
\hline Real Estate & -0.761 & $(0.23)$ & 1.003 & $(0.08)$ & 0.109 & $(0.07)$ & 0.943 & $(0.13)$ & 0.718 \\
\hline Other Financials & -0.054 & $(0.25)$ & 1.298 & $(0.07)$ & 0.297 & $(0.07)$ & 0.106 & $(0.18)$ & 0.748 \\
\hline IT Hardware & 1.367 & $(1.14)$ & 1.412 & $(0.27)$ & 0.845 & $(0.49)$ & -0.904 & $(0.82)$ & 0.253 \\
\hline Software & 0.649 & $(0.47)$ & 1.136 & $(0.11)$ & 0.857 & $(0.22)$ & -0.461 & $(0.24)$ & 0.505 \\
\hline
\end{tabular}




\section{Table IV}

Time Series Regressions of Excess Industrial Returns on the Three Fama-French Factors (Germany)

This table reports the regression results of excess industry portfolio returns on the three Fama-French factors for Germany with sample period from January 1988 to December 1999. The Newey-West adjusted standard errors are reported in parentheses to the right of the coefficient estimates.

\begin{tabular}{lcccccccccc}
\hline Industry & \multicolumn{2}{c}{ Constant } & \multicolumn{2}{c}{$R_{m}-$ Tbill } & \multicolumn{2}{c}{$R_{S M B}$} & \multicolumn{2}{c}{$R_{H M L}$} & Adj. $R^{2}$ \\
\hline Autos & -0.343 & $(0.34)$ & 1.118 & $(0.09)$ & -0.287 & $(0.14)$ & 0.179 & $(0.19)$ & 0.736 \\
Banks & -0.220 & $(0.23)$ & 0.911 & $(0.07)$ & -0.255 & $(0.08)$ & 0.378 & $(0.12)$ & 0.782 \\
Chemicals & -0.058 & $(0.25)$ & 0.825 & $(0.08)$ & -0.239 & $(0.09)$ & 0.308 & $(0.10)$ & 0.698 \\
Media & 1.126 & $(0.67)$ & 0.853 & $(0.14)$ & 0.454 & $(0.16)$ & -0.656 & $(0.26)$ & 0.229 \\
BSC Resources & 0.082 & $(0.27)$ & 1.120 & $(0.08)$ & 0.463 & $(0.09)$ & 0.223 & $(0.12)$ & 0.663 \\
Food \& Beverages & -0.205 & $(0.17)$ & 0.851 & $(0.06)$ & 0.612 & $(0.07)$ & -0.034 & $(0.07)$ & 0.618 \\
Technology & -0.010 & $(0.31)$ & 1.081 & $(0.07)$ & -0.090 & $(0.09)$ & 0.018 & $(0.11)$ & 0.698 \\
Insurance & 0.075 & $(0.29)$ & 1.010 & $(0.08)$ & -0.167 & $(0.11)$ & -0.234 & $(0.17)$ & 0.712 \\
Transportation \& Logistics & -0.048 & $(0.43)$ & 1.190 & $(0.13)$ & 0.280 & $(0.17)$ & 0.305 & $(0.13)$ & 0.463 \\
Machinery & -0.554 & $(0.25)$ & 1.244 & $(0.06)$ & 0.481 & $(0.08)$ & 0.215 & $(0.09)$ & 0.753 \\
Industrial & 1.252 & $(0.43)$ & 1.071 & $(0.11)$ & -0.010 & $(0.11)$ & -0.251 & $(0.24)$ & 0.584 \\
Construction & -0.483 & $(0.39)$ & 1.475 & $(0.10)$ & 1.003 & $(0.17)$ & 0.036 & $(0.11)$ & 0.586 \\
Pharmaceutical \& Health & 0.440 & $(0.26)$ & 0.878 & $(0.06)$ & 0.274 & $(0.11)$ & -0.261 & $(0.12)$ & 0.555 \\
Retail & -0.376 & $(0.37)$ & 1.247 & $(0.13)$ & 0.593 & $(0.10)$ & -0.185 & $(0.14)$ & 0.546 \\
Software & 2.578 & $(0.83)$ & 1.434 & $(0.15)$ & 0.467 & $(0.22)$ & -0.087 & $(0.25)$ & 0.308 \\
Telecom & 0.284 & $(0.67)$ & 0.738 & $(0.13)$ & 0.076 & $(0.18)$ & -0.397 & $(0.27)$ & 0.170 \\
Utilities & 0.063 & $(0.23)$ & 0.689 & $(0.07)$ & -0.009 & $(0.09)$ & 0.222 & $(0.08)$ & 0.594 \\
Financial Services & 0.552 & $(0.33)$ & 0.935 & $(0.13)$ & 0.518 & $(0.14)$ & -0.123 & $(0.12)$ & 0.408 \\
Consumer Cyclical & -0.541 & $(0.40)$ & 1.188 & $(0.08)$ & 0.604 & $(0.11)$ & 0.082 & $(0.14)$ & 0.545 \\
\hline
\end{tabular}


Table V

Time Series Regressions of Excess Industrial Returns on the Three Fama-French Factors

$$
\text { (Japan) }
$$

This table reports the regression results of excess industry portfolio returns on the three Fama-French factors for Japan with sample period from January 1988 to December 1999. The Newey-West adjusted standard errors are reported in parentheses to the right of the coefficient estimates.

\begin{tabular}{|c|c|c|c|c|c|c|c|c|c|}
\hline Industry & \multicolumn{2}{|c|}{ Constant } & \multicolumn{2}{|c|}{$R_{m}-$ Tbill } & \multicolumn{2}{|c|}{$\overline{R_{S M B}}$} & \multicolumn{2}{|c|}{$R_{H M L}$} & Adj. $R^{2}$ \\
\hline Air Transport & 0.194 & $(0.57)$ & 0.909 & $(0.11)$ & 0.151 & $(0.12)$ & -0.049 & $(0.26)$ & 0.348 \\
\hline Banks & 0.315 & $(0.62)$ & 0.964 & $(0.09)$ & -0.133 & $(0.11)$ & 0.117 & $(0.15)$ & 0.388 \\
\hline Chemical & 0.010 & $(0.18)$ & 1.076 & $(0.04)$ & 0.164 & $(0.06)$ & -0.097 & $(0.09)$ & 0.853 \\
\hline Communication & 0.998 & $(0.63)$ & 1.158 & $(0.10)$ & -0.105 & $(0.10)$ & -0.658 & $(0.19)$ & 0.481 \\
\hline Construction & -0.504 & $(0.35)$ & 1.065 & $(0.08)$ & 0.241 & $(0.11)$ & 0.344 & $(0.23)$ & 0.605 \\
\hline Electronic Equipment & 0.007 & $(0.33)$ & 0.950 & $(0.07)$ & -0.171 & $(0.09)$ & 0.047 & $(0.34)$ & 0.555 \\
\hline Utilities & -0.040 & $(0.35)$ & 0.913 & $(0.09)$ & -0.539 & $(0.11)$ & 0.698 & $(0.37)$ & 0.467 \\
\hline Fisheries & -0.526 & $(0.30)$ & 0.999 & $(0.07)$ & 0.497 & $(0.10)$ & 0.193 & $(0.17)$ & 0.628 \\
\hline Foods & -0.008 & $(0.27)$ & 0.894 & $(0.05)$ & 0.218 & $(0.07)$ & -0.011 & $(0$. & 0.728 \\
\hline Glass \& Ceramics & -0.039 & $(0.23)$ & 1.057 & $(0.05)$ & 0.105 & $(0.05)$ & -0.179 & $(0$. & 0.797 \\
\hline Insurance & 0.337 & $(0.43)$ & 1.107 & $(0.09)$ & -0.392 & $(0.10)$ & 0.219 & $(0$. & 0.559 \\
\hline Steel & -0.382 & $(0.50)$ & 1.131 & $(0.06)$ & -0.085 & $(0.11)$ & 0.271 & $(0$. & 0.581 \\
\hline Land Transport & 0.306 & $(0.35)$ & 1.017 & $(0.08)$ & -0.013 & $(0.09)$ & 0.179 & $(0$. & 0.522 \\
\hline Machinery & -0.202 & $(0.19)$ & 1.071 & $(0.04)$ & 0.358 & $(0.06)$ & -0.011 & $(0$. & 0.859 \\
\hline Marine Transport & -0.566 & $(0.50)$ & 1.293 & $(0.09)$ & 0.314 & $(0.14)$ & 0.164 & $(0$. & 0.584 \\
\hline Metal Products & -0.278 & $(0.24)$ & 0.947 & $(0.06)$ & 0.582 & $(0.08)$ & 0.312 & $(0$. & 0.711 \\
\hline Mining & -0.241 & $(0.44)$ & 1.093 & $(0.06)$ & 0.605 & $(0.08)$ & -0.381 & $(0.13)$ & 0.573 \\
\hline Non-ferrous Metals & -0.021 & $(0.22)$ & 1.169 & $(0.05)$ & 0.080 & $(0.06)$ & -0.185 & $(0.12)$ & 0.774 \\
\hline Oil \& Coal & -0.409 & $(0.41)$ & 1.021 & $(0.09)$ & 0.200 & $(0.11)$ & -0.009 & $(0.13)$ & 0.533 \\
\hline Other Financials & -0.131 & $(0.40)$ & 1.037 & $(0.06)$ & 0.208 & $(0.10)$ & 0.153 & $(0.12)$ & 0.635 \\
\hline Other Products & 0.251 & $(0.28)$ & 0.832 & $(0.05)$ & 0.140 & $(0.10)$ & 0.016 & $(0.16)$ & 0.649 \\
\hline Pharmaceutical & 0.282 & $(0.32)$ & 0.800 & $(0.06)$ & 0.003 & $(0.07)$ & -0.136 & $(0.12)$ & 0.531 \\
\hline Precision Instruments & 0.174 & $(0.36)$ & 0.922 & $(0.08)$ & 0.107 & $(0.08)$ & -0.247 & $(0.30)$ & 0.558 \\
\hline Paper & -0.287 & $(0.30)$ & 0.824 & $(0.10)$ & 0.235 & $(0.09)$ & 0.171 & $(0.12)$ & 0.524 \\
\hline Real Estate & 0.081 & $(0.33)$ & 1.267 & $(0.13)$ & -0.307 & $(0.16)$ & 0.355 & $(0.36)$ & 0.536 \\
\hline Retail & 0.039 & $(0.24)$ & 0.908 & $(0.05)$ & 0.224 & $(0.07)$ & 0.249 & $(0.10)$ & 0.702 \\
\hline Rubber & 0.437 & $(0.30)$ & 1.033 & $(0.05)$ & 0.133 & $(0.11)$ & 0.068 & $(0.12)$ & 0.675 \\
\hline Securities & -0.002 & $(0.52)$ & 1.506 & $(0.17)$ & -0.391 & $(0.15)$ & 0.347 & $(0.20)$ & 0.621 \\
\hline Service & 0.174 & $(0.34)$ & 0.922 & $(0.06)$ & 0.361 & $(0.09)$ & 0.167 & $(0.13)$ & 0.679 \\
\hline Textiles & -0.289 & $(0.22)$ & 0.999 & $(0.04)$ & 0.236 & $(0.08)$ & 0.071 & $(0.13)$ & 0.769 \\
\hline Transport Equipment & 0.200 & $(0.21)$ & 0.910 & $(0.04)$ & -0.302 & $(0.08)$ & 0.183 & $(0.16)$ & 0.716 \\
\hline Warehouse & -0.206 & $(0.31)$ & 1.113 & $(0.08)$ & 0.326 & $(0.11)$ & 0.425 & $(0.27)$ & 0.625 \\
\hline Wholesale & -0.359 & $(0.22)$ & 1.079 & $(0.05)$ & 0.095 & $(0.07)$ & 0.133 & $(0.10)$ & 0.830 \\
\hline
\end{tabular}


Table VI

Summary Statistics for Extracted Risk-free Rate Differentials, CPI Inflation Differentials, and Foreign Exchange Rate Changes

This table reports the mean and standard deviation of extracted risk-free rate differentials from the Fama-French Three Factor Model, official (CPI) inflation differentials, and foreign exchange rate changes. The inflation differential is the difference between a foreign and the U.S. extracted risk-free rate rates. The foreign exchange rate is measured as foreign currency per U.S. dollar. The CPI inflation is calculated from the CPI index. The correlations between the variables are also reported.

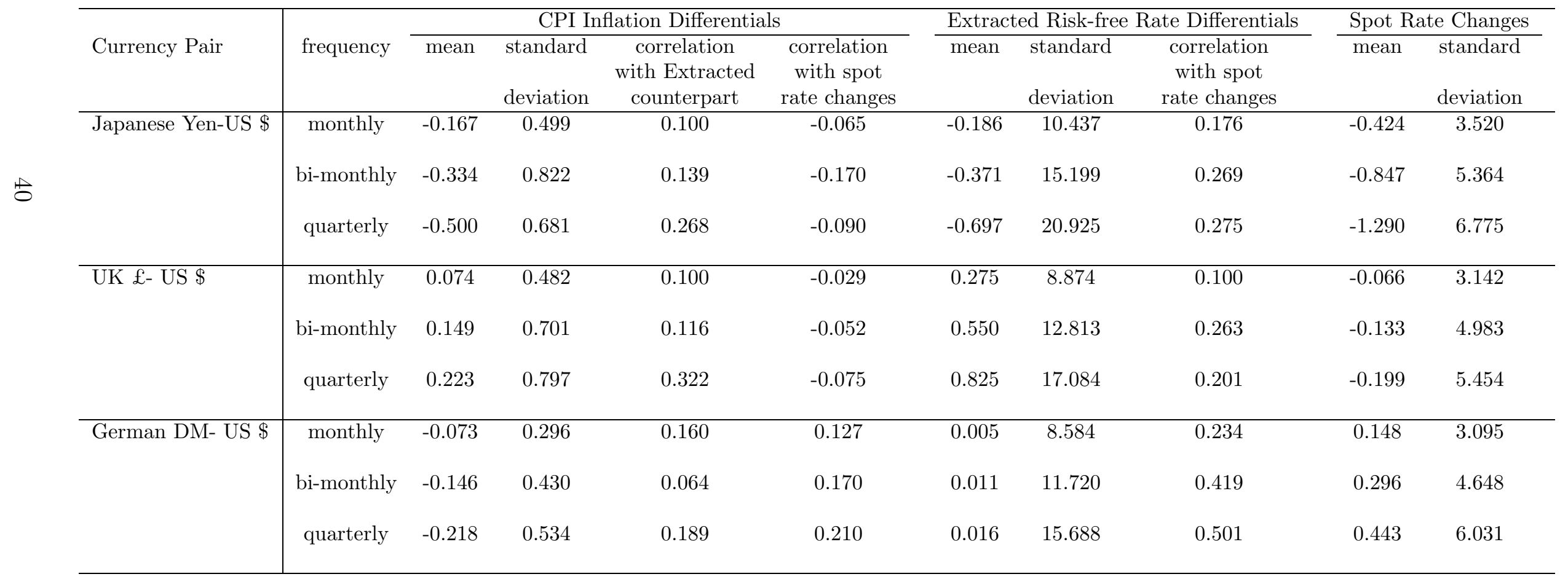


Table VII

PPP Regression Results using Extracted Risk-free Rate from the Fama-French Three Factor Model

This table reports the results of testing the relative PPP hypothesis by regressing the estimated inflation differential on the change in the nominal exchange rate, $R_{f t}^{*}-R_{f t}=a+b \Delta s_{t}+\epsilon_{t}$. The change in the foreign exchange rate is measured as yen or British pounds or Deutsche Marks per U.S. dollar. Newey-West adjusted standard errors are reported in parentheses, $n$ stands for the number of observations. The bootstrap point estimates and the standard errors are reported as well. The $p$ value refers to the $p$-value of the joint F-test for the null hypothesis: intercept=0 and slope $=1$.

\begin{tabular}{|c|c|c|c|c|c|c|c|c|c|}
\hline \multirow[b]{2}{*}{ Currency Pair } & \multirow[b]{2}{*}{ frequency } & \multirow[b]{2}{*}{$n$} & \multicolumn{3}{|c|}{ OLS Results } & \multicolumn{2}{|c|}{ Bootstrap Results } & \multicolumn{2}{|c|}{$H_{0}: a=0$ and $b=1$} \\
\hline & & & $a$ & $b$ & Adj. $R^{2}$ & $a$ & $b$ & $F(2, n-2)$ & $p$-value \\
\hline \multirow[t]{3}{*}{ Japanese Yen-US \$ } & monthly & 200 & $\begin{array}{c}0.036 \\
(0.639)\end{array}$ & $\begin{array}{c}0.522 \\
(0.250)^{*}\end{array}$ & 0.026 & $\begin{array}{c}0.028 \\
(0.700)\end{array}$ & $\begin{array}{c}0.535 \\
(0.220)^{*}\end{array}$ & 2.706 & 0.069 \\
\hline & bi-monthly & 100 & $\begin{array}{c}0.276 \\
(1.021)\end{array}$ & $\begin{array}{c}0.763 \\
(0.337)^{*}\end{array}$ & 0.063 & $\begin{array}{c}0.281 \\
(1.473)\end{array}$ & $\begin{array}{c}0.769 \\
(0.294)^{*}\end{array}$ & 0.421 & 0.658 \\
\hline & quarterly & 66 & $\begin{array}{c}0.398 \\
(1.404)\end{array}$ & $\begin{array}{c}0.849 \\
(0.395)^{*}\end{array}$ & 0.061 & $\begin{array}{c}0.411 \\
(2.343)\end{array}$ & $\begin{array}{c}0.882 \\
(0.382)^{*}\end{array}$ & 0.111 & 0.895 \\
\hline \multirow[t]{3}{*}{ UK £- US $\$$} & monthly & 168 & $\begin{array}{c}0.294 \\
(0.732)\end{array}$ & $\begin{array}{c}0.283 \\
(0.189)\end{array}$ & 0.004 & $\begin{array}{c}0.292 \\
(0.669)\end{array}$ & $\begin{array}{c}0.275 \\
(0.219)\end{array}$ & 5.534 & 0.005 \\
\hline & bi-monthly & 84 & $\begin{array}{c}0.640 \\
(1.436)\end{array}$ & $\begin{array}{c}0.677 \\
(0.150)^{*}\end{array}$ & 0.058 & $\begin{array}{c}0.632 \\
(1.372)\end{array}$ & $\begin{array}{c}0.672 \\
(0.220)^{*}\end{array}$ & 0.494 & 0.613 \\
\hline & quarterly & 56 & $\begin{array}{c}0.950 \\
(2.254)\end{array}$ & $\begin{array}{c}0.631 \\
(0.352)^{* *}\end{array}$ & 0.023 & $\begin{array}{c}0.892 \\
(2.186)\end{array}$ & $\begin{array}{c}0.578 \\
(0.412)\end{array}$ & 0.820 & 0.444 \\
\hline \multirow[t]{3}{*}{ German DM- US $\$$} & monthly & 144 & $\begin{array}{l}-0.091 \\
(0.667)\end{array}$ & $\begin{array}{c}0.648 \\
(0.227)^{*}\end{array}$ & 0.048 & $\begin{array}{l}-0.087 \\
(0.686)\end{array}$ & $\begin{array}{c}0.651 \\
(0.212)^{*}\end{array}$ & 1.230 & 0.295 \\
\hline & bi-monthly & 72 & $\begin{array}{c}-0.302 \\
(1.209)\end{array}$ & $\begin{array}{c}1.056 \\
(0.276)^{*}\end{array}$ & 0.164 & $\begin{array}{l}-0.318 \\
(1.222)\end{array}$ & $\begin{array}{c}1.073 \\
(0.298)^{*}\end{array}$ & 0.047 & 0.954 \\
\hline & quarterly & 48 & $\begin{array}{l}-0.562 \\
(1.587)\end{array}$ & $\begin{array}{c}1.303 \\
(0.380)^{*}\end{array}$ & 0.235 & $\begin{array}{c}-0.631 \\
(1.979)\end{array}$ & $\begin{array}{c}1.302 \\
(0.320)^{*}\end{array}$ & 0.440 & 0.647 \\
\hline
\end{tabular}

*: significantly different from zero at $5 \%$.

**: significantly different from zero at $10 \%$. 
Table VIII

PPP Regression Results using Extracted Risk-free Rate Using Momentum as an Additional Factor

This table reports the results of testing the relative PPP hypothesis by regressing the estimated inflation differential on the change in the nominal exchange rate, $R_{f t}^{*}-R_{f t}=a+b \Delta s_{t}+\epsilon_{t}$. The change in the foreign exchange rate is measured as yen or British pounds or Deutsche Marks per U.S. dollar. Newey-West adjusted standard errors are reported in parentheses, $n$ stands for the number of observations. The bootstrap point estimates and the standard errors are reported as well. The $p$ value refers to the $p$-value of the joint F-test for the null hypothesis: intercept $=0$ and slope $=1$.

\begin{tabular}{|c|c|c|c|c|c|c|c|c|c|}
\hline \multirow[b]{2}{*}{ Currency Pair } & \multirow[b]{2}{*}{ frequency } & \multirow[b]{2}{*}{$n$} & \multicolumn{3}{|c|}{ OLS Results } & \multicolumn{2}{|c|}{ Bootstrap Results } & \multicolumn{2}{|c|}{$H_{0}: a=0$ and $b=1$} \\
\hline & & & $a$ & $b$ & Adj. $R^{2}$ & $a$ & $b$ & $F(2, n-2)$ & $p$-value \\
\hline \multirow[t]{3}{*}{ Japanese Yen - US $\$$} & monthly & 200 & $\begin{array}{c}0.059 \\
(0.678)\end{array}$ & $\begin{array}{c}0.577 \\
(0.259)^{*}\end{array}$ & 0.031 & $\begin{array}{c}0.036 \\
(0.740)\end{array}$ & $\begin{array}{c}0.589 \\
(0.228)^{*}\end{array}$ & 2.005 & 0.137 \\
\hline & bi-monthly & 100 & $\begin{array}{c}0.364 \\
(1.146)\end{array}$ & $\begin{array}{c}0.867 \\
(0.355)^{*}\end{array}$ & 0.074 & $\begin{array}{c}0.356 \\
(1.489)\end{array}$ & $\begin{array}{c}0.881 \\
(0.308)^{*}\end{array}$ & 0.152 & 0.859 \\
\hline & quarterly & 66 & $\begin{array}{c}0.425 \\
(1.577)\end{array}$ & $\begin{array}{c}0.903 \\
(0.413)^{*}\end{array}$ & 0.062 & $\begin{array}{c}0.431 \\
(2.450)\end{array}$ & $\begin{array}{c}0.919 \\
(0.425)^{*}\end{array}$ & 0.052 & 0.950 \\
\hline \multirow[t]{3}{*}{ UK £- US $\$$} & monthly & 168 & $\begin{array}{c}0.296 \\
(0.744)\end{array}$ & $\begin{array}{c}0.326 \\
(0.196)^{* *}\end{array}$ & 0.007 & $\begin{array}{c}0.305 \\
(0.689)\end{array}$ & $\begin{array}{c}0.326 \\
(0.225)\end{array}$ & 4.791 & 0.010 \\
\hline & bi-monthly & 84 & $\begin{array}{c}0.648 \\
(1.458)\end{array}$ & $\begin{array}{c}0.742 \\
(0.146)^{*}\end{array}$ & 0.067 & $\begin{array}{c}0.581 \\
(1.394)\end{array}$ & $\begin{array}{c}0.752 \\
(0.212)^{*}\end{array}$ & 0.541 & 0.584 \\
\hline & quarterly & 56 & $\begin{array}{c}0.975 \\
(2.298)\end{array}$ & $\begin{array}{c}0.756 \\
(0.351)^{*}\end{array}$ & 0.036 & $\begin{array}{c}0.870 \\
(2.323)\end{array}$ & $\begin{array}{c}0.710 \\
(0.430)^{* *}\end{array}$ & 0.256 & 0.775 \\
\hline \multirow[t]{3}{*}{ German DM - US $\$$} & monthly & 144 & $\begin{array}{l}-0.091 \\
(0.672)\end{array}$ & $\begin{array}{c}0.650 \\
(0.227)^{*}\end{array}$ & 0.048 & $\begin{array}{l}-0.077 \\
(0.690)\end{array}$ & $\begin{array}{c}0.654 \\
(0.212)^{*}\end{array}$ & 1.214 & 0.300 \\
\hline & bi-monthly & 72 & $\begin{array}{c}-0.302 \\
(1.223)\end{array}$ & $\begin{array}{c}1.055 \\
(0.277)^{*}\end{array}$ & 0.163 & $\begin{array}{l}-0.309 \\
(1.216)\end{array}$ & $\begin{array}{c}1.056 \\
(0.312)^{*}\end{array}$ & 0.046 & 0.955 \\
\hline & quarterly & 48 & $\begin{array}{l}-0.561 \\
(1.587)\end{array}$ & $\begin{array}{c}1.301 \\
(0.380)^{*}\end{array}$ & 0.231 & $\begin{array}{l}-0.565 \\
(1.979)\end{array}$ & $\begin{array}{c}1.311 \\
(0.320)^{*}\end{array}$ & 0.428 & 0.650 \\
\hline
\end{tabular}

*: significantly different from zero at $5 \%$.

**: significantly different from zero at $10 \%$. 


\section{Table IX}

\section{Seemingly Unrelated PPP Regressions for Three Country Pairs}

This table reports the results of testing the relative PPP hypothesis by using the seemingly unrelated system equations (SUR) across all three country-pairs. The estimated inflation differential is regressed on the change in the nominal exchange rate, $\left[\begin{array}{l}R_{f t, J P}^{*}-R_{f t, U S} \\ R_{f t, U K}^{*}-R_{f t, U S} \\ R_{f t, G e r}^{*}-R_{f t, U S}\end{array}\right]=\left[\begin{array}{l}a_{1} \\ a_{2} \\ a_{3}\end{array}\right]+\left[\begin{array}{ccc}\Delta s_{t, J P} & 0 & 0 \\ 0 & \Delta s_{t, U K} & 0 \\ 0 & 0 & \Delta s_{t, G e r}\end{array}\right]\left[\begin{array}{l}b_{1} \\ b_{2} \\ b_{3}\end{array}\right]+\epsilon_{t}$. The change in the foreign exchange rate is measured as yen or British pounds or Deutsch Marks per U.S. dollar. Newey-West adjusted standard errors are reported in parentheses, and $n$ stands for the number of observations for the system.

\begin{tabular}{|c|c|c|c|c|c|c|c|c|}
\hline \multirow[b]{3}{*}{ Currency Pair } & \multicolumn{8}{|c|}{ Panel A: SUR FGLS Estimates } \\
\hline & \multirow[b]{2}{*}{ frequency } & \multirow[b]{2}{*}{$n$} & \multicolumn{3}{|c|}{ Three Factor Model } & \multicolumn{3}{|c|}{ Momentum as a 4 th Factor } \\
\hline & & & $a$ & $b$ & System $R^{2}$ & $a$ & $b$ & System $R^{2}$ \\
\hline Japanese Yen-US $\$$ & Monthly & 512 & $\begin{array}{c}-0.032 \\
(0.730)\end{array}$ & $\begin{array}{c}0.362 \\
(0.192)^{* *}\end{array}$ & 0.016 & $\begin{array}{l}-0.020 \\
(0.753)\end{array}$ & $\begin{array}{c}0.391 \\
(0.196)^{*}\end{array}$ & 0.017 \\
\hline UK £- US \$ & & & $\begin{array}{c}0.349 \\
(0.675)\end{array}$ & $\begin{array}{c}0.152 \\
(0.203)\end{array}$ & & $\begin{array}{c}0.359 \\
(0.682)\end{array}$ & $\begin{array}{c}0.174 \\
(0.203)\end{array}$ & \\
\hline German DM- US \$ & & & $\begin{array}{l}-0.067 \\
(0.692)\end{array}$ & $\begin{array}{c}0.530 \\
(0.219)^{*}\end{array}$ & & $\begin{array}{l}-0.086 \\
(0.692)\end{array}$ & $\begin{array}{c}0.517 \\
(0.219)^{*}\end{array}$ & \\
\hline Japanese Yen-US $\$$ & bi-monthly & 256 & $\begin{array}{c}0.094 \\
(1.477)\end{array}$ & $\begin{array}{c}0.542 \\
(0.252)^{*}\end{array}$ & 0.067 & $\begin{array}{c}0.124 \\
(1.556)\end{array}$ & $\begin{array}{c}0.584 \\
(0.258)^{*}\end{array}$ & 0.065 \\
\hline UK £- US $\$$ & & & $\begin{array}{c}0.749 \\
(1.341)\end{array}$ & $\begin{array}{c}0.491 \\
(0.252)^{* *}\end{array}$ & & $\begin{array}{c}0.775 \\
(1.371)\end{array}$ & $\begin{array}{c}0.501 \\
(0.251)^{* *}\end{array}$ & \\
\hline German DM- US \$ & & & $\begin{array}{l}-0.241 \\
(1.262)\end{array}$ & $\begin{array}{c}0.968 \\
(0.271)^{*}\end{array}$ & & $\begin{array}{l}-0.251 \\
(1.264)\end{array}$ & $\begin{array}{c}0.943 \\
(0.270)^{*}\end{array}$ & \\
\hline Japanese Yen-US $\$$ & Quarterly & 170 & $\begin{array}{c}0.295 \\
(2.503)\end{array}$ & $\begin{array}{c}0.661 \\
(0.341)^{* *}\end{array}$ & 0.085 & $\begin{array}{c}0.327 \\
(2.641)\end{array}$ & $\begin{array}{c}0.686 \\
(0.350)^{*}\end{array}$ & 0.077 \\
\hline UK £- US $\$$ & & & $\begin{array}{c}1.051 \\
(2.236)\end{array}$ & $\begin{array}{c}0.450 \\
(0.391)\end{array}$ & & $\begin{array}{c}1.074 \\
(2.309)\end{array}$ & $\begin{array}{c}0.497 \\
(0.395)\end{array}$ & \\
\hline German DM- US \$ & & & $\begin{array}{c}-0.433 \\
(1.978)\end{array}$ & $\begin{array}{c}1.147 \\
(0.326)^{*}\end{array}$ & & $\begin{array}{l}-0.462 \\
(1.986)\end{array}$ & $\begin{array}{c}1.083 \\
(0.323)^{*}\end{array}$ & \\
\hline
\end{tabular}

*: significantly different from zero at $5 \%$.

**: significantly different from zero at $10 \%$. 
Table IX

Seemingly Unrelated PPP Regressions for Three Country Pairs (continued)

\begin{tabular}{|c|c|c|c|c|c|c|c|}
\hline \multirow[b]{3}{*}{$H_{0}$} & \multicolumn{7}{|c|}{ Panel B: Hypothesis Testing } \\
\hline & \multirow[b]{2}{*}{ Frequency } & \multirow[b]{2}{*}{$D f_{1}$} & \multirow[b]{2}{*}{$D f_{2}$} & \multicolumn{2}{|c|}{ Three Factor Model } & \multicolumn{2}{|c|}{ Momentum as a 4 th U.S.Factor } \\
\hline & & & & $F\left(D f_{1}, D f_{2}\right)$ & $p$-value & $F\left(D f_{1}, D f_{2}\right)$ & $p$-value \\
\hline \multirow{3}{*}{$a_{1}=a_{2}=a_{3}=0$} & monthly & 3 & 506 & 0.119 & 0.950 & 0.126 & 0.946 \\
\hline & bi-monthly & 3 & 250 & 0.128 & 0.945 & 0.136 & 0.940 \\
\hline & quarterly & 3 & 164 & 0.094 & 0.964 & 0.101 & 0.960 \\
\hline \multirow[t]{3}{*}{$b_{1}=b_{2}=b_{3}=0$} & monthly & 3 & 506 & 2.865 & 0.036 & 2.916 & 0.034 \\
\hline & bi-monthly & 3 & 250 & 6.247 & $<0.001$ & 6.129 & $<0.001$ \\
\hline & quarterly & 3 & 164 & 5.220 & 0.002 & 4.779 & 0.003 \\
\hline \multirow[t]{3}{*}{$b_{1}=b_{2}=b_{3}$} & monthly & 2 & 506 & 0.911 & 0.406 & 0.785 & 0.462 \\
\hline & bi-monthly & 2 & 250 & 0.981 & 0.379 & 0.788 & 0.460 \\
\hline & quarterly & 2 & 164 & 1.032 & 0.362 & 0.742 & 0.482 \\
\hline \multirow[t]{3}{*}{$b_{1}=b_{2}=b_{3}=1$} & monthly & 3 & 506 & 8.865 & $<0.001$ & 8.296 & $<0.001$ \\
\hline & bi-monthly & 3 & 250 & 2.109 & 0.102 & 1.817 & 0.150 \\
\hline & quarterly & 3 & 164 & 0.943 & 0.426 & 0.730 & 0.541 \\
\hline \multirow{4}{*}{$\begin{array}{l}a_{1}=a_{2}=a_{3}=0 \\
\text { and } \\
b_{1}=b_{2}=b_{3}=1\end{array}$} & & & & & & & \\
\hline & monthly & 6 & 506 & 4.507 & $<0.001$ & 4.213 & $<0.001$ \\
\hline & bi-monthly & 6 & 250 & 1.126 & 0.352 & 0.982 & 0.448 \\
\hline & quarterly & 6 & 164 & 0.527 & 0.790 & 0.423 & 0.867 \\
\hline
\end{tabular}


Table X

Constrained System of Equations PPP Regression for Three Country Pairs

This table reports the results of testing the relative PPP hypothesis of the constrained system equations across all three country-pairs. The estimated inflation differential is regressed on the change in the nominal exchange rate, $\left[\begin{array}{c}R_{f t, J P}^{*}-R_{f t, U S} \\ R_{f t, U K}^{*}-R_{f t, U S} \\ R_{f t, G e r}^{*}-R_{f t, U S}^{*}\end{array}\right]=a+\left[\begin{array}{c}\Delta s_{t, J P} \\ \Delta s_{t, U K} \\ \Delta s_{t, G e r}\end{array}\right] b+\epsilon_{t}$. The change in the foreign exchange rate is measured as yen or British pounds or Deutsche Marks per U.S. dollar. Newey-West adjusted standard errors are reported in parentheses. The bootstrap point estimates and the standard errors are reported as well, and $n$ stands for the number of observations for the system. For the bootstrap procedure, to guard against the possibility of underestimation of standard errors because of potential cross correlation among the three country pairs, only $n_{3}<n / 3$, the total number of observations for the Germany-U.S. pair, observations are drawn from the original sample with replacement; thus reported standard errors represent upper bounds. The $p$ value refers to the $p$-value of the joint F-test for the null hypothesis: intercept $=0$ and slope $=1$.

\begin{tabular}{|c|c|c|c|c|c|c|c|c|c|}
\hline \multirow[b]{2}{*}{ Currency Pair } & \multirow[b]{2}{*}{ frequency } & \multirow[b]{2}{*}{$n$} & \multicolumn{3}{|c|}{ OLS Results } & \multicolumn{2}{|c|}{ Bootstrap Results } & \multicolumn{2}{|c|}{$H_{0}: a=0$ and $b=1$} \\
\hline & & & $a$ & $b$ & Adj. $R^{2}$ & $a$ & $b$ & $F(2, n-2)$ & $p$-value \\
\hline & & & & & anel A: T & Factor & odel & & \\
\hline \multirow[t]{3}{*}{ System of equations } & monthly & 512 & $\begin{array}{c}0.089 \\
(0.389)\end{array}$ & $\begin{array}{c}0.482 \\
(0.141)^{*}\end{array}$ & 0.026 & $\begin{array}{c}0.034 \\
(0.769)\end{array}$ & $\begin{array}{c}0.497 \\
(0.246)^{*}\end{array}$ & 8.644 & 0.0002 \\
\hline & bi-monthly & 256 & $\begin{array}{c}0.272 \\
(0.753)\end{array}$ & $\begin{array}{c}0.803 \\
(0.175)^{*}\end{array}$ & 0.087 & $\begin{array}{c}0.261 \\
(1.499)\end{array}$ & $\begin{array}{c}0.820 \\
(0.321)^{*}\end{array}$ & 0.847 & 0.430 \\
\hline & quarterly & 170 & $\begin{array}{c}0.546 \\
(1.139)\end{array}$ & $\begin{array}{c}0.903 \\
(0.222)^{*}\end{array}$ & 0.109 & $\begin{array}{c}0.531 \\
(2.291)\end{array}$ & $\begin{array}{c}0.907 \\
(0.396)^{*}\end{array}$ & 0.244 & 0.784 \\
\hline
\end{tabular}

Panel B: Four Factor Model

\begin{tabular}{|c|c|c|c|c|c|c|c|c|c|}
\hline \multirow[t]{3}{*}{ System of Equations } & monthly & 512 & $\begin{array}{c}0.095 \\
(0.400)\end{array}$ & $\begin{array}{c}0.520 \\
(0.144)^{*}\end{array}$ & 0.030 & $\begin{array}{c}0.114 \\
(0.805)\end{array}$ & $\begin{array}{c}0.525 \\
(0.254)^{*}\end{array}$ & 7.171 & 0.0008 \\
\hline & bi-monthly & 256 & $\begin{array}{c}0.291 \\
(0.781)\end{array}$ & $\begin{array}{c}0.869 \\
(0.182)^{*}\end{array}$ & 0.095 & $\begin{array}{c}0.276 \\
(1.551)\end{array}$ & $\begin{array}{c}0.878 \\
(0.331)^{*}\end{array}$ & 0.394 & 0.675 \\
\hline & quarterly & 170 & $\begin{array}{c}0.527 \\
(1.189)\end{array}$ & $\begin{array}{c}0.988 \\
(0.226)^{*}\end{array}$ & 0.121 & $\begin{array}{c}0.557 \\
(2.323)\end{array}$ & $\begin{array}{c}0.981 \\
(0.402)^{*}\end{array}$ & 0.094 & 0.910 \\
\hline
\end{tabular}

*: significantly different from zero at 5\%.

${ }^{* *}$ : significantly different from zero at $10 \%$. 


\section{Table XI}

\section{Cointegration Relation Between the CPI and the Constructed Price Index}

This table reports the Johansen test of cointegration between the price index, $P_{R_{f}, t}$, which is constructed from the extracted series $\hat{R}_{f t}$, and the official price index CPI. The cointegration regression results are also reported with the asymptotic $t$-ratios in the brackets. Panel A reports the analysis using the price indices themselves while Panel B reports the results using logged price indices.

\begin{tabular}{|c|c|c|c|c|}
\hline \multirow[b]{2}{*}{ Currency } & \multicolumn{3}{|c|}{ Cointegration Regression } & \multirow{2}{*}{$\begin{array}{c}\text { Johansen Test } \\
\text { Null: no cointegration }\end{array}$} \\
\hline & Intercept & $\hat{c}_{1}$ & LL & \\
\hline \multicolumn{5}{|c|}{ Panel A: Price Indices } \\
\hline GM & $\begin{array}{r}-1.842 \\
{[1.75]}\end{array}$ & $\begin{array}{l}1.672 \\
{[2.07]}\end{array}$ & 778.0 & Reject \\
\hline JP & $\begin{array}{l}0.368 \\
{[0.43]}\end{array}$ & $\begin{array}{l}0.318 \\
{[0.43]}\end{array}$ & 986.3 & Reject \\
\hline UK & $\begin{array}{c}-10.972 \\
{[2.96]}\end{array}$ & $\begin{array}{l}4.806 \\
{[2.24]}\end{array}$ & 639.7 & Reject \\
\hline US & $\begin{array}{r}-1.082 \\
{[2.88]}\end{array}$ & $\begin{array}{l}0.989 \\
{[3.94]}\end{array}$ & 1088.2 & Reject \\
\hline
\end{tabular}

Panel B: Logged Price Indices

\begin{tabular}{lcccc} 
GM & -1.434 & 2.747 & 824.1 & Reject \\
& {$[2.45]$} & {$[4.40]$} & & \\
JP & -0.395 & 0.686 & 1025.4 & Reject \\
& {$[3.06]$} & {$[0.80]$} & & \\
UK & -7.745 & 9.196 & 848.8 & Reject \\
& {$[2.96]$} & {$[2.24]$} & & \\
US & -0.899 & 1.658 & 1220.7 & Reject \\
& {$[7.19]$} & {$[7.24]$} & & \\
\hline
\end{tabular}




\section{References}

Adler, Michael and Lehman, Bruce, 1983, Deviations from purchasing power parity in the long run, Journal of Finance 38, 157-174.

Ang, Andrew, and Geert Bekaert, 2001, Stock return predictability: is it there?, Working paper, Columbia University.

Barr, David G. and John Y. Campbell, 1997, Inflation, real interest rates, and the bond market:

A study of UK nominal and index-linked government bond prices, Journal of Monetary Economics 39, 361-383.

Baxter, M., 1994, Real exchange rates and real interest rate differentials: have we missed the business-cycle relationship?, Journal of Monetary Economics 33, 5-37.

Bleaney, M. and D. Laxton, 2003, Real interest rates and real exchange rates: evidence from indexed bonds, The Manchester School 71, 65-77.

Boudoukh, Jacob, Matthew Richardson, Robert F. Whitelaw, 1994, Industry Returns and the Fisher Effect, Journal of Finance 49, 1594-1615.

Carhart, Mark M., 1997, On persistence in mutual fund performance, Journal of Finance 52, 57-82.

Cochrane, J.H., 2001, Asset Pricing, Princeton University Press.

Delgado, F.A., 1991, Hysteresis, menu costs, and pricing with random exchange rates, Journal of Monetary Economics 28, 461-484.

Dixit, A., 1989a. Entry and exit decision under uncertainty. Journal of Political Economy 97, 620-638.

Dixit, A., 1989b. Hysteresis, import penetration, and exchange rate pass-through. Quarterly 
Journal of Economics 104, 205-228.

Dornbusch, Rudiger, 1976, Expectations and exchange rate dynamics, Journal of Political Economy 84, 1161-1176.

Edison, H. J., and B. D. Pauls, 1993, A re-assessment of the relationship between real exchange rates and real interest rates, Journal of Monetary Economics 31, 149-164.

Efron, B., and R.J. Tibshirani, 1994, An introduction to the bootstrap, CRC Press.

Fama, E.F., and K. R. French, 1995. Size and book-to-market factors in earnings and returns, Journal of Finance 50, 131-156.

Fama, E.F., and J.D. MacBeth, 1973. Risk, return, and equilibrium: empirical tests. Journal of Political Economy 81, 607-636.

Griffin, John M., 2002, Are the Fama and French factors global or country-specific?, Review of Financial Studies 15, 783-803.

Karolyi, G.A., and R.M. Stulz, 2003, Are financial assets priced locally or globally?, in George Constantinides, Milton Harris and Ren Stulz, eds.: The Handbook of the Economics of Finance (Elsevier, North-Holland.).

Krugman, P., 1986. Pricing to market when the exchange rate changes. NBER Working Paper NO. 1926.

Mankiw, N. Gregory, 1985, Small menu costs and large business cycles: a macroeconomic model of monopoly, Quarterly Journal of Economics 100, 529-537.

Mussa, Michael, 1982, A model of exchange rate dynamics, Journal of Political Economy 90, $74-104$.

Newey, W.K., and K.D. West, 1987. A simple, positive semi-definite, heteroskedasticity and 
autocorrelation consistent covariance matrix. Econometrica 55, 703-708.

Pagan, A., 1984. Econometric issues in the analysis of regressions with generated regressors. International Economic Review 25, 221-247.

Rogoff, Kenneth, 1996, The purchasing power parity puzzle, Journal of Economic Literature $34,647-668$.

Rogoff, Kenneth, 1998, Perspectives on exchange rate volatility, in Martin Feldstein, ed.: International Capital Flows (NBER and University of Chicago Press, Chicago, Illinois.).

Rogoff, Kenneth, 2002, Dornbusch's overshooting model after twenty-five years, MundellFleming Lecture, Second Annual Research Conference, International Monetary Fund, Washington, D.C.

Rotemberg, J., 1982. Sticky prices in the United States. Journal of Political Economy 90, 1187-1211.

Shanken, Jay, 1992, On the estimation of beta pricing models, Review of Financial Studies 5, $1-34$.

Stock, James H., Watson, Mark W., 2003, Forecasting output and inflation: the role of asset prices, Journal of Economic Literature 41, 788-829.

Zhang, Xiaoyan, 2003, Specification tests of international asset pricing models, Working paper, Cornell University. 